
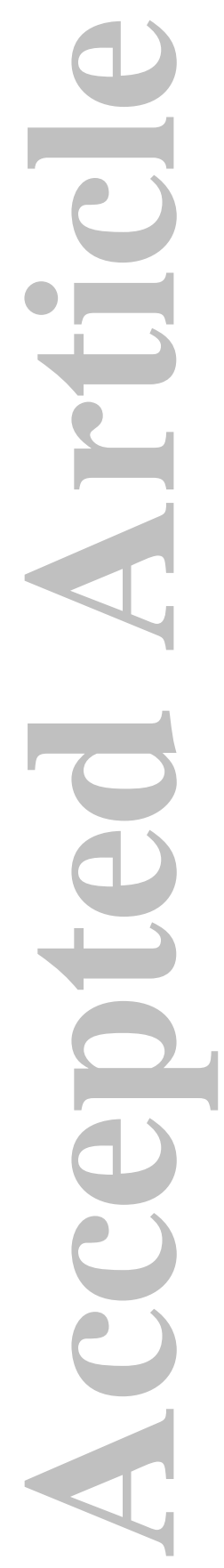

This is the author manuscript accepted for publication and has undergone full peer review but has not been through the copyediting, typesetting, pagination and proofreading process, which may lead to differences between this version and the Version record. Please cite this article as doi:10.1002/ mds.27098.

This article is protected by copyright. All rights reserved. 


\section{Pedunculopontine nucleus deep brain stimulation in Parkinson's disease: A clinical review}

Wesley Thevathasan, DPhil FRACP, ${ }^{1}$ Bettina Debu, PhD, ${ }^{2}$ Tipu Aziz, FRCS, ${ }^{3}$ Bastiaan R. Bloem, MD PhD, ${ }^{4}$ Christian Blahak, MD ${ }^{5}$ Christopher Butson, $\mathrm{PhD},{ }^{6}$ Virginie Czernecki, $\mathrm{PhD},{ }^{7}$ Thomas Foltynie, PhD FRCP ${ }^{8}$ Valerie Fraix, MD PhD, ${ }^{2}$ David Grabli, MD PhD, ${ }^{9}$ Carole Joint, RN PhD, ${ }^{3}$ Andres M. Lozano, MD PhD,${ }^{10}$ Michael S. Okun, MD, ${ }^{11}$ Jill Ostrem, MD, ${ }^{12}$ Nicola Pavese, PhD FRCP,${ }^{13}$ Christoph Schrader, MD,${ }^{14}$ Chun-Hwei Tai, MD, ${ }^{15}$ Joachim K. Krauss, MD, ${ }^{16}$ Elena Moro MD PhD, ${ }^{2}$

On behalf of the MDS PPN DBS working group in collaboration with WSSFN*

1. Department of Medicine, Royal Melbourne Hospital, University of Melbourne, Australia and the Bionics Institute of Australia, Melbourne, Australia

2. Movement Disorders Center, Division of Neurology, CHU Grenoble, Grenoble Alpes University, Grenoble, France

3. Department of Neurosurgery, John Radcliffe Hospital, University of Oxford, UK

4. Department of Neurology, Donders Institute for Brain, Cognition and Behaviour, Radboud University, Nijmegen, the Netherlands

5. Department of Neurology, Universitätsmedizin Mannheim, University of Heidelberg, Heidelberg, Germany

6. Department of Bioengineering, Scientific Computing and Imaging (SCI) Institute, University of Utah, Salt Lake City, USA

7. Department of Neurology, Institut de Cerveau et de la Moelle épinière, Sorbonne Universités, UPMC Université, Paris, France

8. Sobell Department of Motor Neuroscience, UCL Institute of Neurology, United Kingdom

9. Department of Neurology, Assistance Publique-Hôpitaux de Paris, Pitié-Salpêtière University Hospital, Paris, France

10. Department of Neurosurgery, Toronto Western Hospital, University of Toronto, Toronto, Canada

11. Departments of Neurology and Neurosurgery, University of Florida Center for Movement Disorders, Gainseville, USA 
12. Department of Neurology, UCSF Movement Disorder and Neuromodulation Center, University of California, San Francisco, USA

13. Institute of Neuroscience, Newcastle University, Newcastle upon Tyne, UK and Department of Clinical Medicine, Centre for Functionally Integrative Neuroscience, University of Aarhus, Aarhus, Denmark and Department of Neurology, Hannover Medical School, Hannover, Germany

14. Department of Neurology, National Taiwan University Hospital, College of Medicine, National Taiwan University, Taipei, Taiwan

15. Department of Neurosurgery, Hannover Medical School, Hannover, Germany

* See Appendix

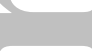

Corresponding author:

Elena Moro, MD, PhD

Centre Hospitalier Universitaire de Grenoble, Grenoble Alpes University

BP21738043 Grenoble CEDEX 09 France

$\mathrm{Fax}+33476765631$

E-mail: emoro@,chu-grenoble.fr

$$
\text { (1) }
$$

$\sqrt{10}$

Word count: 4988

Running Title: Clinical review of PPN DBS

Key words: deep brain stimulation, gait freezing, Parkinson's disease, pedunculopontine nucleus

Financial disclosure/Conflict of interest: The MDS PPN DBS working group in collaboration with WSSFN was supported by an unrestricted educational grant from Medtronic.

Disclosures from individual authors are cited on each copyright transfer form.

Funding sources: The MDS PPN DBS working group in collaboration with WSSFN was supported by an unrestricted educational grant from Medtronic. 


\section{ABSTRACT}

Pedunculopontine nucleus region deep brain stimulation (DBS) is a promising but experimental therapy for axial motor deficits in Parkinson's disease (PD), particularly gait freezing and falls. Here, we summarise the clinical application and outcomes reported over the last 10 years. The published dataset is limited - comprising less than a hundred cases. Furthermore, there is great variability in clinical methodology, both between and within surgical centres. The commonest indication has been severe medication refractory gait freezing (often associated with postural instability). Some patients received lone pedunculopontine nucleus DBS (unilateral or bilateral) and some received co-stimulation of the subthalamic nucleus or internal pallidum. Both rostral and caudal pedunculopontine nucleus subregions have been targeted. However, spread of stimulation and variance in targeting means that neighbouring brainstem regions may be implicated in any response. Low stimulation frequencies are typically employed (20-80 Hertz). The fluctuating nature of gait freezing can confound programming and outcome assessments. Whilst firm conclusions cannot be drawn on therapeutic efficacy, the literature suggests that medication refractory gait freezing and falls can improve. The impact on postural instability is unclear. Most groups report a lack of benefit on gait or limb akinesia or dopaminergic medication requirements. The key question is whether pedunculopontine nucleus DBS can improve quality of life in PD. So far, the evidence supporting such an effect is minimal. Development of pedunculopontine nucleus DBS to become a reliable, established therapy would likely require a collaborative effort between experienced centres to clarify biomarkers predictive of response and the optimal clinical methodology. 


\section{INTRODUCTION}

The pedunculopontine nucleus (PPN, also known as the pedunculopontine tegmental nucleus or PPTg) is a collection of heterogeneous neurons at the junction of the midbrain and pons. ${ }^{1,2}$ PPN neurons express a range of neurotransmitters but perhaps most prominently acetylcholine. ${ }^{2}$ The PPN displays substantial reciprocal connectivity with the cortex via the thalamus, basal ganglia, and spinal cord. ${ }^{3}$ A long and rich history of research in animals suggests that the PPN may affect locomotion, the startle response, states of arousal and even reward. ${ }^{4-8}$ Of relevance to gait, the PPN has been considered a key component of the “Mesencephalic Locomotor Region' - an area where electrical stimulation in decerebrated animals can induce locomotor-like activity, although the relevance of this concept to the therapeutic impact of PPN DBS is debated..$^{2,3}$

PPN DBS has developed as an experimental therapy for axial motor deficits in Parkinson's disease (PD), particularly those which are poorly responsive to subthalamic nucleus (STN) and globus pallidus internus (GPi) DBS. ${ }^{9-11}$ Axial deficits such as gait freezing and postural instability are major contributors to impaired quality of life in PD. The initial emergence of PPN DBS, therefore, raised much excitement. However, it became apparent that the therapeutic outcomes from PPN DBS were variable and often disappointing, both within and between surgical centres. ${ }^{12-16}$ This variability may reflect a fundamental limitation of the target or alternatively that the methodology has not been optimised yet.

To try and progress the field, a Working Group was approved as a bi-societal endeavour of the international Movement Disorders Society (MDS) and the World Society for Stereotactic and Functional Neurosurgery (WSSFN). This group encompasses neurologists, neurosurgeons, neurophysiologists, neuropsychologists, and electrical engineers with 
expertise on the PPN and/or PPN DBS. The initial objective was to summarise, analyse and publish on the state of the field.

The surgical aspects of this work (surgical anatomy and techniques) have been recently published in a specialized neurosurgical journal. ${ }^{17}{ }^{18}$ This paper deals with medical aspects of PPN DBS including the clinical application and outcomes to date.

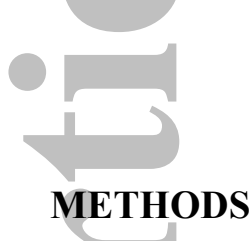

\section{Literature search}

The PubMed database was searched from 1990 to March 2017 using the key words: deep brain stimulation, Parkinson's disease, pedunculopontine nucleus, surgery, treatment. Only publications in English reporting clinical outcomes of PPN DBS in PD were selected.

\section{Questions and consensus process}

The Executive Committee of the Working Group formulated several questions which were distributed to groups of authors according to their expertise - as with previous Task Forces. ${ }^{19}$, ${ }^{20}$ The answers were organized into the manuscript, and reviewed by the Executive Committee and the complete task force at multiple international meetings. Areas of disagreement were discussed and modified according to Delphi techniques until consensus was reached. ${ }^{21}$ The literature was updated during the work.

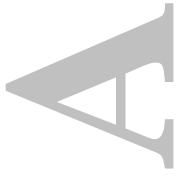

\section{RESULTS}

Less than 100 patients with PD implanted with PPN DBS have been published. 9, 10, 12-16, 22-27 Between and even within surgical centres, there has been substantial variation and often 
evolution in clinical methodology. Therefore, we must acknowledge the many limitations and confounds from these reports. First, the clinical application of PPN DBS employed so far does not necessarily reflect the optimal methodology. Secondly, the location of where therapeutic effects from stimulation arise has not been established yet. For example, electrodes have been implanted in both rostral and caudal PPN subregions. ${ }^{25,26}$ Furthermore, in some cases, stimulation may actually have been directed at networks involving neighbouring structures including the cuneiform and peripeduncular nuclei. ${ }^{27,28}$ In any case, the range of stimulation parameters typically employed means that a range of networks may be implicated in any response. ${ }^{24,28}$ For example, the differing stimulation frequencies applied to the PPN (10 to $80 \mathrm{~Hz}$ ) may affect the selectivity of neural elements. ${ }^{29}$ For this reason, we always imply stimulation of the PPN region when we discuss PPN DBS. Thirdly, the limited and heterogeneous dataset prevents us drawing firm conclusions regarding the scope of clinical impact. This dataset includes case reports, open label series, double blinded single time point assessments, and longer term double blinded studies (table). Finally, PPN DBS has evolved as a treatment for axial motor impairment, particularly gait freezing and falls. The impact of PPN DBS on other domains have generally been reported as incidental observations.

\section{Clinical application}

\section{Indication}

After initial reports suggested improvement in gait freezing from PPN DBS in PD, the typical indications became medication refractory gait freezing and falls. ${ }^{9,12-14,16}$ Therefore, most patients implanted with PPN DBS have fallen into one of these two groups; 
1. Patients with PD who exhibit early and severe gait freezing resistant to medication as the dominant cause of disability are candidates for lone PPN DBS. ${ }^{30}$ This is an unusual subgroup, perhaps comprising around $5 \%$ of patients with PD. ${ }^{30}$ Indeed, some of these patients may later declare features of an atypical parkinsonian disorder. ${ }^{31}$ Patients with medication responsive freezing and motor fluctuations are candidates for established therapies such as STN or GPi DBS. ${ }^{32,33}$

2. Patients with PD who develop medication resistant gait freezing during STN or GPi DBS can be candidate for PPN DBS. ${ }^{12,15,22,25}$ However, co-stimulation of both the PPN and STN/GPi could cause an interaction between stimulation at these sites. ${ }^{34}$ On the one hand, this could be synergistic, with STN or GPi DBS adding improvement to akinesia and 'off' freezing compared with lone PPN DBS. ${ }^{22}$ On the other hand, high frequency STN or GPi DBS could transmit to the PPN via their extensive reciprocal connections and counteract PPN DBS. ${ }^{2,7,35}$

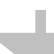

\section{Target selection}

The exact location and the anatomical boundaries of the PPN are controversial. ${ }^{36-38}$

Furthermore, the precise location of stimulation in the brainstem is poorly reflected by commissural coordinates. Therefore, some studies have reported the location of PPN stimulation relative to local landmarks. A detailed discussion on the surgical anatomy and targeting is found in our companion papers. ${ }^{17,18}$ The following two issues are raised as important for understanding the medical management of PPN DBS.

\section{Rostral vs. Caudal PPN stimulation}

Over time, two topographic regions of the PPN have been posited, rostral and caudal. Studies have reported spatially segregated patterns of local field potentials recorded from PPN 
electrodes in patients with PD. Alpha band oscillations in the caudal subregion (around 4mm below the pontomesencephalic junction) were reported to correlate with gait and freezing, ${ }^{37}$ whereas beta band oscillations in the rostral subregion (around the level of the inferior colliculus) were not found to correlate with gait (real or imagined). ${ }^{37,39}$ Two studies reported very limited clinical data that further raised the hypothesis that caudal PPN DBS may be more effective than rostral PPN DBS for gait freezing. ${ }^{37,40}$ Given the surgical trajectory usually runs along the long axis of the PPN, it is feasible to target both subregions with the same electrode giving the option to activate either.

\section{Unilateral vs. Bilateral PPN Stimulation}

The relative efficacy of unilateral versus bilateral PPN stimulation is controversial. Some practitioners elected to implant unilaterally, given the bilateral connectivity of each PPN and the greater risks inherent in bilateral implantation. ${ }^{2,13}$ In a small double blind study employing spatiotemporal gait analysis, bilateral PPN stimulation in seven patients was reported as more effective than unilateral PPN stimulation for 'off medication' gait freezing. ${ }^{41}$ Additionally, some patients implanted with unilateral PPN DBS, have been reported to further benefit from contralateral PPN implantation. ${ }^{42}$

\section{Outcome assessments}

A common method to assess outcomes has been the Unified Parkinson's disease rating scale (UPDRS). ${ }^{43}$ The 'pull test' item of the UPDRS was the only method used in most studies to assess postural instability, however this test is said to suffer poor reliability and scaling (score/4). ${ }^{44}$ Gait freezing exhibits substantial fluctuation which makes accurate measurement difficult. Some studies of PPN DBS employed specific instruments to capture gait freezing such as the Gait and Falls Questionnaire (GFQ, score/64), and the Freezing of Gait 
Questionnaire (FOGQ, score/24). ${ }^{45,46}$ Even fewer studies employed objective laboratory methods including spatiotemporal gait analysis using a walkway with embedded pressure sensors, step tracking with shoe mounted pressure sensors, and fast Fourier transformation of trunk accelerometer data. ${ }^{12,37,41}$ However, such laboratory methods can confounded by the propensity of freezing to disappear under observation. ${ }^{47}$ Some studies therefore employed potent triggers of gait freezing such as turning on the spot in a confined space. ${ }^{12,41}$ Individual studies have attempted to assess non-motor deficits such as sleep, cognition, psychiatric state, quality of life and adverse events using instruments commonly used to assess DBS in PD. ${ }^{48}$

\section{Postoperative management}

\section{Programming}

Titration of PPN DBS can be complex and time consuming. Factors include the fluctuating nature of gait freezing, the unpredictable degree of benefit and the prolonged latencies (days to weeks) reported for benefits to emerge. ${ }^{12-14}$ Furthermore, an acute microlesion or 'stun' effect has been described where gait freezing improves in the early postoperative period prior to activation of stimulation. ${ }^{16,37,49}$

The major stimulation variables explored have been stimulation location along the electrode (see discussion of rostral vs caudal DBS above) and frequency. Other reported parameters have been fairly restricted (e.g. typical pulse width range $60-90$ usec, $^{13,35}$ and voltage range from 0.8 to $3.6 \mathrm{~V}$ ) with monopolar or bipolar configuration. ${ }^{12,13,23}$

All studies have reported that low frequencies $(<80 \mathrm{~Hz})$ of PPN DBS seem optimal for motor deficits. Studies of bilateral PPN DBS have reported that 20-35 Hz stimulation was useful for gait freezing. ${ }^{12,14,22,23}$ One study found that patients responded best to higher frequencies (60 $-80 \mathrm{~Hz}){ }^{13}$ This study differed in two critical respects - the use of unilateral rather than 
bilateral PPN DBS and the additional goal of treating co-morbid postural instability. ${ }^{13}$ Two studies have specifically investigated frequency effects of PPN DBS in PD. One study explored differing very low frequencies $(5-35 \mathrm{~Hz})$ on reaction time. ${ }^{23}$ This study found that 20-35 Hz PPN DBS was superior to $5 \mathrm{~Hz}$ and $10 \mathrm{~Hz}$ stimulation. ${ }^{23}$ Another study directly compared the impact of bilateral low frequency $(10-25 \mathrm{~Hz})$ versus higher frequency $(60-80$ Hz) PPN DBS on gait freezing, akinesia and sleepiness. ${ }^{35}$ Seven of nine patients had less gait freezing with low frequency PPN DBS. ${ }^{35}$ Bilateral higher frequency PPN DBS was associated with worsened akinesia and sleepiness.

\section{Titration of medication and stimulation of other targets}

The lack of benefit of PPN DBS on akinesia (see below) has meant that either dopaminergic medication or co-stimulation of conventional targets (STN or GPi) has been required to maintain the 'on' state. ${ }^{12,14}$ PPN DBS has not been widely reported to substantially change dopaminergic medical requirements. In some patients, an ideal motor benefit was achieved by reducing the high frequencies normally employed in the STN (e.g. from $130 \mathrm{~Hz}$ to $80 \mathrm{~Hz}$ ) during co-stimulation of the PPN. ${ }^{15,50}$ Even with lone STN DBS, it has been reported that lower stimulation frequencies may improve 'on' freezing, so it is unclear if this represents a specific interaction between the two stimulation locations. ${ }^{51}$

\section{Stimulation and implantation side effects}

Reversible side effects resulting from PPN region DBS or the microlesion effect from implantation mostly relate likely to involvement of neighbouring structures. ${ }^{17}$ These include:

1. Sensory phenomena. Contralateral paraesthesia likely reflects current spread to the medial lemniscus. ${ }^{12,22,52}$ This typically habituates over seconds to minutes. A more profound and even painful sensation may reflect spread into the more lateral spinothalamic tract. ${ }^{52}$ In a 
single case stimulation caused ipsilateral pain consistent with spread to the trigeminal nucleus. ${ }^{53}$

2. Oscillopsia. Typically, reported by patients as 'shimmering' vision. Infra-red eye tracking demonstrates nystagmus at the frequency of DBS ipsilateral to stimulation. Stimulation of fibres in the uncinate fasciculus of the cerebellum and the superior cerebellar peduncle (which in turn stimulate the saccadic premotor neurones) is hypothesized. ${ }^{54}$

3. Limb myoclonus. This may reflect involvement of the ipsilateral cerebellar peduncle/decussation. ${ }^{12}$

4. Urge urinary incontinence with phasic detrusor over activity. This was described in a patient from the time of implantation and which recovered over months. ${ }^{55}$ The nearby pontine micturition centre was implicated. ${ }^{55}$

\section{$\underline{\text { Outcomes }}$}

\section{Motor Impact}

\section{Gait freezing}

Short term $(<2$ years $)$

Reduced gait freezing appears to be the major therapeutic benefit of PPN DBS, evident from the earliest reports. ${ }^{9,}{ }^{24}$ However, the evidence base remains modest, with studies being small (up to ten patients) and ranging from unblinded open label series to double blinded studies with controls. ${ }^{12-16,41}$ These studies suggest that PPN DBS can improve gait freezing in some patients, in both off and on medication states. ${ }^{13,41}$ Two surgical centres (Toronto and Grenoble) employed unilateral or bilateral stimulation to the rostral PPN, and reported variable and overall modest improvements. ${ }^{12,13}$ Another two surgical centres (Oxford and Brisbane), applied bilateral stimulation to the caudal PPN region, and also reported modest 
but more substantial benefits. ${ }^{14,41}$ Two more surgical centres (Rome and Bristol) reported that PPN DBS improved motor function including gait, but did not isolate gait freezing as a separate outcome measure. ${ }^{15,50,56,57}$ There are also single case reports of PPN DBS in PD with overall mixed results. ${ }^{25,26}$

Some inferences regarding the degree of efficacy of PPN DBS on freezing can be attempted by using selected studies that reported scores from individual patients. ${ }^{12-14,41}$ Pooled results from three studies that reported individual scores for item 14 (freezing) of the UPDRS part II, revealed an overall improvement with PPN DBS of $30 \%(\mathrm{~N}=15$, mean score $2.2 / 4$ reduced to 1.5/4) when on medication. ${ }^{12,13,16}$ Results of patients from two centres assessed with the GFQ (reflecting function whilst medicated) revealed an improvement of 39\% (N=7, mean 45.7 to 27.7$).{ }^{58}$ One double-blind controlled study assessed freezing using spatiotemporal gait analysis while off medication, and reported an overall $64.6 \%$ improvement $(\mathrm{N}=7$, freezing duration 31.1 to 11.0 seconds). ${ }^{41}$ Thus, so far, PPN DBS has been reported to partially improve but not abolish gait freezing. Whether such partial benefits are clinically meaningful is unclear but perhaps captured in quality of life assessments (see below). Furthermore, there is insufficient data to comment on whether PPN DBS differentially affects all the various aspects of gait freezing that have been described.

Longer term (> 2 years)

One recent paper reported the outcomes at four years after unilateral PPN DBS implantation in six patients with PD, with double blinded assessments off and on stimulation (two weeks in each condition). ${ }^{42}$ There was persistent benefit in four of the six patients on gait freezing and falls.

\section{Other aspects of Gait}


Two studies suggested that PPN DBS could alter a variety of spatiotemporal parameters during unconstrained gait - that is, when walking freely straight ahead. ${ }^{57,59}$ However, these studies had methodological issues, including a set order of conditions, unblinded assessments, the potential influence of fluctuating medication state and washout of STN DBS. ${ }^{59}$ In contrast, in a double-blinded, controlled study employing spatiotemporal gait analysis, the impact of lone PPN DBS on gait was assessed when off medication. ${ }^{41}$ This study reported a benefit of PPN DBS on gait freezing. During unconstrained walking, patients with freezing had reduced step length and increased step length variability compared to patients without freezing. However, these deficits were unchanged by PPN DBS. ${ }^{41}$ This study suggests that the impact of PPN DBS differs from that of levodopa and STN DBS, which improve step length and thereby presumably also improve off medication freezing. ${ }^{47,60}$ Therefore, the therapeutic benefits of PPN and STN DBS (or levodopa) on gait would be predicted to be complementary although this remains to be formally tested.

\section{Balance}

The impact of PPN DBS on overall balance is uncertain.

Improved postural instability was specifically cited as a potential benefit in one of the earliest reports of PPN DBS. ${ }^{9}$ However, few studies have specifically isolated the impact on postural instability - and any benefit has been variable and often not detected. ${ }^{9,12,13,16}$ One issue may be the shortcomings in the assessment tool for postural instability used by these studies - the clinical 'pull test' (item 30 of the UPDRS part III and item 3.12 of the MDS-UPDRS, score/4). ${ }^{43,61}$ The pull test may not be sufficiently sensitive or reliable to detect a clinically meaningful change. ${ }^{14,44}$ Another issue may relate to DBS programming as it has been suggested that different frequencies of stimulation may be needed to improve postural instability compared with gait freezing. ${ }^{35}$ Further research is needed into this area. 
Two recent papers suggest that other aspects of balance may be modulated by PPN DBS. ${ }^{16,27}$ In these studies, PPN DBS appeared to alter measures of postural sway in centre of pressure during stance. ${ }^{16}$ In one study, PPN DBS improved anticipatory postural adjustments. ${ }^{16}$ In another study, PPN DBS (during STN stimulation) appeared to improve vestibular perceptual thresholds. ${ }^{27}$ The net functional consequences of such effects remain to be established.

\section{Falls}

An improvement in falls frequency with PPN DBS has been documented using item 13 of the UPDRS part II (score/4), components of the Rating Scale for Gait Evaluation and the GFQ, and patient diaries. ${ }^{12-14,16,23,42}$ Fewer falls with PPN DBS has been a consistently reported therapeutic benefit, occurring even in studies where any benefit on freezing or postural instability was modest or not found. ${ }^{13,23}$ This could reflect that falls frequency is a more certain and sensitive biomarker of the response to PPN DBS. It is unclear if falls are reduced due to less freezing, less postural instability, or another mechanism (for example, a paradoxical reduction in falls due to less ambulation or greater use of gait aids has not been excluded). In two studies, reduced falls were unrelated to freezing, which suggests that the effect is somewhat independent of any reduction in gait freezing. ${ }^{13,23}$ The benefit of PPN DBS on falls is reported to endure over the long term in one study. ${ }^{42}$

\section{Axial deformity}

Two reports describe an apparent benefit of unilateral PPN DBS on Pisa syndrome. In one report, the electrode was contralateral to the side of lateral lean and improvement was sustained over 14 months, and documented with videotape assessment. ${ }^{62}$ In the other report, the electrode was ipsilateral to the side of lateral lean and improvement wore off over 3 years. The effect in this case was documented with a wall mounted goniometer. ${ }^{63}$ Such findings 
seem to mirror the debate regarding whether the direction of lean in Pisa syndrome relates to the side most affected by parkinsonism. ${ }^{64}$

\section{Speech}

Three studies have specifically assessed the impact of PPN DBS on speech. ${ }^{65-67}$ In an initial study, unilateral PPN DBS was suggested to improve oromotor movements, raising hopes that speech could improve.$^{65}$ However, a recent double-blinded study of six patients found that bilateral PPN DBS worsened measures of phonation time and speech diadokokinesis with overall mixed effects on speech intelligibility. ${ }^{67}$ Considering the current evidence, it is not clear whether the overall impact of PPN DBS on speech is helpful or detrimental.

\section{Akinesia, rigidity and tremor}

Almost all studies of PPN DBS have observed no substantial benefit on akinesia, rigidity or tremor as assessed by items $1-26$ of the UPDRS part III. ${ }^{12-14,22}$ However, one group has consistently reported a possible benefit of PPN DBS on these items, both off and on medication. ${ }^{9}, 15,50,56$ These patients were generally also receiving STN DBS raising the possibility that persistent washout effects could have influenced the results. Furthermore, PPN DBS does not significantly change dopaminergic medication requirements and there is additional motor benefit following STN DBS. ${ }^{12,22}$ PPN DBS does not uniformly yield the

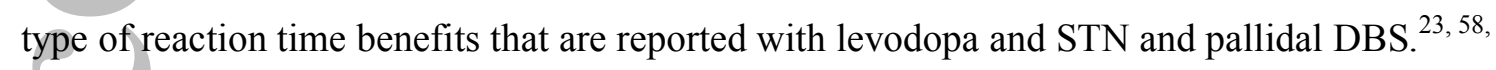
${ }^{68,69}$ Furthermore, double blinded spatiotemporal gait analysis has revealed no change to step length with PPN DBS. ${ }^{41}$ Importantly, in one double-blind study, bilateral PPN DBS applied at medium frequencies $(60-80 \mathrm{~Hz})$ significantly worsened akinesia scores compared with low frequency stimulation $(15-25 \mathrm{~Hz})^{7,35,70}$

\section{Reaction time}


Studies of at least eight patients that assessed the impact of PPN DBS on reaction time have reported a benefit most prominent in simple reaction time tasks. ${ }^{23,58,71}$ This reaction time benefit was reported to affect the entire reaction time distribution curve and not just outliers, argued to reflect a motor impact rather than augmented attention. ${ }^{23}$ A further study suggested that this motor effect could be isolated to enhanced release of pre-programmed motor responses, supported by the absence of the Start React phenomenon in patients with gait freezing that was restored by PPN DBS. ${ }^{58}$

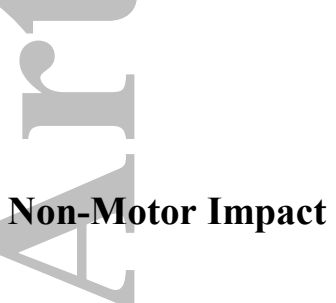

\section{Cognition and mood}

That the PPN comprises part of the reticular activating system has raised the question of whether PPN DBS may improve attention, especially as attentional deficits are implicated in the pathogenesis of gait freezing. ${ }^{72,73}$ A recent study found that bilateral PPN DBS improved simple reaction times without a warning cue but not a go/no-go or divided attention task. ${ }^{71}$ There was a strong trend that PPN DBS also improved simple reaction times with a warning cue $(p=0.07)$. However, on the basis that this latter result was not significant, the authors argued that PPN DBS improved phasic arousal rather than a motor effect. Though, with only eight patients in the study, this may simply reflect insufficient power. Additionally, two further studies (discussed in the section above) suggested that the selective impact of PPN DBS on certain aspects of reaction time is likely due to enhanced motor performance. ${ }^{23,58}$ Thus, it seems currently that there is insufficient evidence to support that PPN DBS augments alertness or general attention.

Several studies of PPN DBS have performed cross sectional cognitive assessments. Two studies found no consistent change in the Mattis Dementia Rating Scale or a composite 
assessment of frontal lobe function in six patients with PPN DBS. ${ }^{12,16}$ However, several studies from the Rome group have reported substantial improvements with PPN DBS on frontal lobe cognition in small numbers of patients. For example, two such studies suggested improvements in performance on an n-back task and various tasks of executive functioning but with limited information regarding the methodology. ${ }^{74,75}$ One case report claimed that PPN DBS improved measures in all tested cognitive domains including attention, memory and language, and was perhaps modulated by attentional improvements although this effect may have been due to intercurrent factors. ${ }^{76}$ These authors also reported that PPN DBS increased prefrontal glucose utilisation using FDG-PET with associated improvements in delayed recall and executive functioning. ${ }^{77}$ However, such frontal changes with PPN DBS were not found on regional cerebral blood flow PET in three other studies, where blood flow changes appeared restricted to subcortical and sensorimotor cortical areas. ${ }^{15,78,79}$

In one study of six patients, PPN DBS did not consistently change scores of the Beck Depression Inventory or the Starkstein Apathy Scale. ${ }^{12}$ In another study of four patients, anxiety and depression did not change, as assessed by questionnaires (Brief Anxiety Scale, Montgomery, and Asberg Depression Scale). ${ }^{16}$ Other major clinical studies (with $\geq 5$ patients) have not formally assessed psychiatric outcomes. ${ }^{13,14,22}$ However, clinically obvious psychiatric effects from PPN DBS were not reported in these studies.

\section{Sleep}

Three studies have specifically assessed whether PPN DBS affects sleep in parkinsonian patients. ${ }^{80-82}$ The results suggest a marked impact on switching between sleep states, particularly the promotion of rapid eye movement (REM) sleep. This is consistent with decades of animal research. ${ }^{83}$ 
Two studies assessed patients using overnight polysomnography, and both reported that PPN DBS roughly doubled the proportion of REM sleep. ${ }^{80,82}$ In one study of 5 patients with PD or PSP, unilateral PPN DBS increased nightly REM sleep time (mean 35 to 61 minutes) and percentage REM sleep (mean 8 to $14 \%$ ) compared with no stimulation. ${ }^{82}$ Importantly, this study found that the increased REM sleep was due to an increased frequency rather than duration of REM sleep episodes. Non-REM sleep was unchanged by PPN DBS. Two patients experienced REM sleep behavioural disturbance and this persisted with PPN DBS.

The increased REM sleep episodes with PPN DBS suggest that there may be an underlying impact on transitioning between sleep states. In support of this notion, an early study detected phasic potentials during and before REM sleep from PPN electrodes consistent with pontogeniculo-occipital waves. ${ }^{84}$ One study reported two patients in whom PPN DBS could provoke sleep from a state of wakefulness, assessed clinically and with electroencephalography. ${ }^{81}$ These patients were alert during low frequency PPN DBS $(10 \mathrm{~Hz}$ or $25 \mathrm{~Hz}$ ). In one patient, abrupt withdrawal of this low frequency PPN DBS reproducibly triggered short periods of REM sleep. In both patients, initiation of high frequency PPN DBS $(80 \mathrm{~Hz})$ could precipitate non-REM sleep.

It is unclear what, if any, functional consequence may result from increased REM sleep with PPN DBS. Some but not all studies suggest that REM sleep may decline in PD. ${ }^{85}$ REM sleep is postulated to improve memory consolidation, particularly that of procedural learning. ${ }^{86}$ Whether this has mechanistic relevance to the motor impact of PPN DBS is unknown.

\section{Surgical risks}

At this stage, there does not appear to be any contraindication that is specific to PPN DBS relative to other forms of DBS for Parkinson's disease. However, patients would need to be 
counselled that the occurrence of even a small haemorrhage in the brainstem could have devastating consequences. ${ }^{16,67}$

\section{Quality of Life}

Two double blinded studies have reported on the impact of PPN DBS on quality of life using the Parkinson's Disease Questionnaire-39 (PDQ-39). One study of six patients found that PPN DBS did not consistently change scores of the PDQ-39. ${ }^{12}$ However in five of six patients, PPN DBS improved scores in the mobility subsection of the PDQ-39. ${ }^{12}$ In a second report of six patients, two patients had severe adverse events (infection requiring device explanation and brainstem hemorrhage). In the remaining four patients in that study, quality of life improved significantly. ${ }^{16}$

\section{DISCUSSION}

Despite more than ten-years history of the use of PPN DBS in patients with PD, the cohort of implanted patients worldwide remains limited. ${ }^{9,}{ }^{10}$ Additionally, only a few centres have generated the bulk of the cases and published literature. ${ }^{12-15,22}$ These factors limit the strength and thus inferences that can be drawn from the dataset.

We have presented a summary of the clinical application of PPN DBS employed to date. Clinical methodologies have varied greatly. For example, in some cases stimulation is even argued to be directed at neighbouring structures including the cuneiform and peripeduncular nuclei. ${ }^{36,87}$ However, it is conceivable that variance in stimulation location could identify a more effective target than the PPN itself. What is evident is that fundamental aspects of the clinical application of PPN DBS remain unclear, including if there are specific biomarkers of 
response to guide patient selection, the ideal stimulation location and parameters of stimulation. Indeed, these areas could interact together, e.g., it is possible that postural instability may benefit from stimulation of a different PPN subregion, and with different stimulation parameters compared with gait freezing. ${ }^{13}$

Whilst acknowledging the limitations of the dataset, the available evidence supports that PPN DBS has the potential to improve gait freezing in both the off and on medication states, and can reduce falls in some patients. ${ }^{12-14,41}$ The impact on postural instability is unclear. The degree of improvement is highly variable - both between and within surgical centres. On average, PPN DBS offers a reduction and not resolution of freezing and falls. There is no known preoperative factor that predicts such benefits. The variability of benefit may reflect the differing clinical methods employed. For example, it is difficult to compare outcomes of patients implanted with lone PPN DBS compared with those also receiving stimulation in other targets (often with reciprocal connections to the PPN). Additionally, axial deficits are difficult to capture with the available clinical scales and more objective measures are needed. ${ }^{44}$ For example, the consistent benefit of PPN DBS on falls across studies may simply reflect that it is an unambiguous and sensitive biomarker of response. Furthermore, it should be acknowledged that disease progression in the subgroup of patients with severe gait freezing and balance disturbance who are suitable for this therapy is often more aggressive. ${ }^{88}$ This means that long term outcomes will be particularly important in gauging success of this intervention.

PPN DBS does not clearly improve other aspects of gait such as gait akinesia. ${ }^{41}$ Moreover, the evidence does not support any benefit for limb akinesia, rigidity or tremor and thus dopaminergic medication requirements do not substantially change after PPN DBS. ${ }^{12,13,23}$ 
Regarding non-motor symptoms, the current evidence does not strongly support any major impact on cognition outside of enhanced motor performance. ${ }^{58}$ PPN DBS appears to increase REM sleep. ${ }^{82}$ Whether this increased REM sleep has any functional consequences, either beneficial or not, is unknown.

The clinically relevant question is whether PPN DBS can improve quality of life in patients with PD. So far, the available evidence supporting this ideal is very modest. ${ }^{12,16}$ It is clearly our hope that refinement of the clinical application of PPN DBS will yield the type of robust and consistent benefits seen with DBS of established targets in PD such as the STN and GPi. However, we acknowledge the less attractive possibility that the therapeutic action of the target itself may be the issue. For example, gait freezing is considered a complex deficit which involves dysfunction in widespread networks including attentional and motor systems, both cortical and brainstem. Relief of the latter may only have capacity to yield a circumscribed benefit. However, even if this were the case, there could still be an identifiable subgroup of patients where this benefit could improve quality of life and/or have a synergistic relationship with other emerging therapies. Of course, any benefit must be contrasted against risks of brainstem implantation.

So, what are the next steps? First, acknowledge that every centre has successes and failures. We need to identify what is different about patients who respond positively, and to identify the key predictors of therapeutic efficacy. To achieve this, we need to pool the experience of centres that implant the PPN. One initial approach would be a multicentre database capturing agreed measures of the clinical application (such as stimulation location) and outcomes. Only once the clinical methodology of PPN DBS has been further developed would it be appropriate to consider a multicentre randomised controlled trial to assess the impact on quality of life. 


\section{ACKNOWLEDGEMENTS}

The MDS PPN DBS working group in collaboration with WSSFN was supported by an unrestricted educational grant from Medtronic.

\section{AUTHORS ROLES}

(1) Research Project: A. Conception, B. Organization, C. Execution;

(2) Statistical Analysis: A. Design, B. Execution, C. Review and Critique;

(3) Manuscript Preparation: A. Writing of the First Draft, B. Review and Critique

WT: 1BC, 3AB. BD: 1C, 3B. TA: 1ABC, 3B. BRB: 1ABC, 3B. C.Blahak: 1C, 3B. C. Butson: 1C, 3B. VC: 1C, 3B. TF: 1C, 3B. VF: 1C, 3B. DG: 1C, 3B. AML: 1ABC, 3B. CJ: 1C, 3B. MSO: 1ABC, 3B. JO: 1C, 3B. NP: 1C, 3B. CS: 1C, 3B. CT: 1C, 3B. JKK: 1ABC, 3B. EM: $1 \mathrm{ABC}, 3 \mathrm{~B}$.

\section{APPENDIX}

The Members of the Pedunculopontine Area DBS Working Group: T. Aziz (United Kingdom); C. Blahak (Germany), B. Bloem (The Netherlands), P. Brown (United Kingdom), C. Butson (USA), S. Chabardes (France), TJ Coyne (Australia), V. Czernecki (France), B. Debu (France), T. Foltynie (United Kingdom), E. Fonoff (Brazil), V. Fraix (France), K. Foote (USA), D. Grabli (France), C. Hamani (Canada), E.C. Hirsch (France), W. Hutchison (Canada), J.K. Krauss (Germany), C. Joint (United Kingdom), AM Lozano (Canada), P. Mazzone (Italy), E. Moro (France), M. Okun (USA), J. Ostrem (USA), N. Pavese (United Kingdom), C. Schrader (Germany), J. Stein (United Kingdom), C-H Tai (Taiwan), W. Thevathasan (Australia), I. Veletzas (Greece).

\section{REFERENCES}

1. Jacobsohn L. Uber die Kerne des menschlichen Hirnstamms:(Medulla oblongata, Pons, und Pedunculus cerebri). Anhang zuden Abhandlungen der Kgl Preuss, Akad d Wiss 1911.

2. Jenkinson N, Nandi D, Muthusamy K, et al. Anatomy, physiology, and pathophysiology of the pedunculopontine nucleus. Mov Disord 2008.

3. Gut NK, Winn P. The pedunculopontine tegmental nucleus-A functional hypothesis from the comparative literature. Mov Disord 2016;31(5):615-624. 
4. Garcia-Rill E, Houser CR, Skinner RD, Smith W, Woodward DJ. Locomotion-inducing sites in the vicinity of the pedunculopontine nucleus. Brain Res Bull 1987;18(6):731-738.

5. Winn P. Experimental studies of pedunculopontine functions: are they motor, sensory or integrative? Parkinsonism Relat Disord 2008;14 Suppl 2:S194-198.

6. Mena-Segovia J, Sims HM, Magill PJ, Bolam JP. Cholinergic brainstem neurons modulate cortical gamma activity during slow oscillations. J Physiol 2008.

7. Jenkinson N, Nandi D, Miall RC, Stein JF, Aziz TZ. Pedunculopontine nucleus stimulation improves akinesia in a Parkinsonian monkey. Neuroreport 2004;15(17):2621-2624.

8. Nandi D, Aziz TZ, Giladi N, Winter J, Stein JF. Reversal of akinesia in experimental parkinsonism by GABA antagonist microinjections in the pedunculopontine nucleus. Brain 2002;125(Pt 11):2418-2430.

9. Plaha P, Gill SS. Bilateral deep brain stimulation of the pedunculopontine nucleus for Parkinson's disease. Neuroreport 2005;16(17):1883-1887.

10. Mazzone $P$, Lozano A, Stanzione $P$, et al. Implantation of human pedunculopontine nucleus: a safe and clinically relevant target in Parkinson's disease. Neuroreport 2005;16(17):1877-1881.

11. Fasano A, Aquino CC, Krauss JK, Honey CR, Bloem BR. Axial disability and deep brain stimulation in patients with Parkinson disease. Nat Rev Neurol 2015;11(2):98-110.

12. Ferraye MU, Debu B, Fraix V, et al. Effects of pedunculopontine nucleus area stimulation on gait disorders in Parkinson's disease. Brain 2009;133(Pt 1):205-214.

13. Moro E, Hamani C, Poon YY, et al. Unilateral pedunculopontine stimulation improves falls in Parkinson's disease. Brain 2010;133(Pt 1):215-224.

14. Thevathasan W, Coyne TJ, Hyam JA, et al. Pedunculopontine nucleus stimulation improves gait freezing in Parkinson disease. Neurosurgery 2011;69(6):1248-1253.

15. Khan S, Gill SS, Mooney L, et al. Combined pedunculopontine-subthalamic stimulation in Parkinson disease. Neurology 2012;78(14):1090-1095.

16. Welter ML, Demain A, Ewenczyk C, et al. PPNa-DBS for gait and balance disorders in Parkinson's disease: a double-blind, randomised study. J Neurol 2015;262(6):1515-1525.

17. Hamani C, Aziz T, Bloem BR, et al. Pedunculopontine Nucleus Region Deep Brain Stimulation in Parkinson Disease: Surgical Anatomy and Terminology. Stereotact Funct Neurosurg 2016;94(5):298-306.

18. Hamani C, Lozano AM, Mazzone PA, et al. Pedunculopontine Nucleus Region Deep Brain Stimulation in Parkinson Disease: Surgical Techniques, Side Effects, and Postoperative Imaging. Stereotact Funct Neurosurg 2016;94(5):307-319.

19. Benabid AL, Deuschl G, Lang AE, Lyons KE, Rezai AR. Deep brain stimulation for Parkinson's disease. Mov Disord 2006;21 Suppl 14:S168-170.

20. Moro E, Albanese A, Krauss JK, Metman LV, Vidailhet M, Hariz MI. Guest editors' introduction. Mov Disord 2011;26 Suppl 1:S1-2.

21. Linstone HA, and Murray Turoff, eds. . The Delphi method: Techniques and applications. . Reading, MA: Addison-Wesley, 1975.

22. Stefani A, Lozano AM, Peppe A, et al. Bilateral deep brain stimulation of the pedunculopontine and subthalamic nuclei in severe Parkinson's disease. Brain 2007;130(Pt 6):15961607.

23. Thevathasan W, Silburn PA, Brooker $\mathrm{H}$, et al. The impact of low-frequency stimulation of the pedunculopontine nucleus region on reaction time in parkinsonism. J Neurol Neurosurg Psychiatry 2010;81(10):1099-1104.

24. Pereira EA, Muthusamy KA, De Pennington N, Joint CA, Aziz TZ. Deep brain stimulation of the pedunculopontine nucleus in Parkinson's disease. Preliminary experience at Oxford. Br J Neurosurg 2008;22 Suppl 1:S41-44.

25. Schrader C, Seehaus F, Capelle HH, Windhagen A, Windhagen H, Krauss JK. Effects of pedunculopontine area and pallidal DBS on gait ignition in Parkinson's disease. Brain stimulation 2013;6(6):856-859. 
26. Liu HG, Zhang K, Yang AC, Zhang JG. Deep brain stimulation of the subthalamic and pedunculopontine nucleus in a patient with Parkinson's disease. J Korean Neurosurg Soc 2015;57(4):303-306.

27. Yousif N, Bhatt H, Bain PG, Nandi D, Seemungal BM. The effect of pedunculopontine nucleus deep brain stimulation on postural sway and vestibular perception. Eur J Neurol 2016;23(3):668-670. 28. Zrinzo L, Zrinzo LV, Tisch S, et al. Stereotactic localization of the human pedunculopontine nucleus: atlas-based coordinates and validation of a magnetic resonance imaging protocol for direct localization. Brain 2008;131(Pt 6):1588-1598.

29. Kringelbach ML, Jenkinson N, Owen SL, Aziz TZ. Translational principles of deep brain stimulation. Nat Rev Neurosci 2007;8(8):623-635.

30. Giladi N, McDermott MP, Fahn S, et al. Freezing of gait in PD: prospective assessment in the DATATOP cohort. Neurology 2001;56(12):1712-1721.

31. Scelzo E, Lozano AM, Hamani C, et al. Peduncolopontine nucleus stimulation in progressive supranuclear palsy: a randomised trial. J Neurol Neurosurg Psychiatry 2017.

32. Deuschl G, Schade-Brittinger C, Krack P, et al. A randomized trial of deep-brain stimulation for Parkinson's disease. N Engl J Med 2006;355(9):896-908.

33. Follett KA, Weaver FM, Stern M, et al. Pallidal versus subthalamic deep-brain stimulation for Parkinson's disease. N Engl J Med 2010;362(22):2077-2091.

34. Ferraye MU, Debu B, Fraix V, et al. Subthalamic nucleus versus pedunculopontine nucleus stimulation in Parkinson disease: synergy or antagonism? J Neural Transm 2011;118(10):1469-1475. 35. Nosko D, Ferraye MU, Fraix V, et al. Low-frequency versus high-frequency stimulation of the pedunculopontine nucleus area in Parkinson's disease: a randomised controlled trial. J Neurol Neurosürg Psychiatry 2014.

36. Zrinzo L, Zrinzo LV, Hariz M. The peripeduncular nucleus: a novel target for deep brain stimulation? Neuroreport 2007;18(12):1301-1302.

37. Thevathasan W, Pogosyan A, Hyam JA, et al. Alpha oscillations in the pedunculopontine nucleus correlate with gait performance in parkinsonism. Brain 2012;135(Pt 1):148-160.

38. Yelnik J. PPN or PPD, what is the target for deep brain stimulation in Parkinson's disease?

Brain 2007;130(Pt 9):e79; author reply e80.

39. Tattersall TL, Stratton PG, Coyne TJ, et al. Imagined gait modulates neuronal network dynamics in the human pedunculopontine nucleus. Nat Neurosci 2014;17(3):449-454.

40. Fu RZ NM, Adams A, et al. . Sub-caudal pedunculopontine nucleus (PPN) deep brain stimulation (DBS) best predicts improvements in freezing of gait questionnaire (FOGQ) scores in Parkinson's disease patients. . Movement Disorders(29 Suppl 1):1193 2014.

41. Thevathasan $\mathrm{W}$, Cole $\mathrm{MH}$, Graepel $\mathrm{CL}$, et al. A spatiotemporal analysis of gait freezing and the impact of pedunculopontine nucleus stimulation. Brain 2012;135(Pt 5):1446-1454.

42. Mestre TA, Sidiropoulos C, Hamani C, et al. Long-term double-blinded unilateral pedunculopontine area stimulation in Parkinson's disease. Movement disorders 2016;31(10):15701574.

43. Fahn S ER, UPDRS program members. Unified Parkinson's Disease Rating Scale In: Fahn S MC, Goldstein M, Calne DB, ed. Recent Developments in Parkinson's Disease. Florham Park, NJ: Macmillan Healthcare Information, 1987:153-163, 293-304.

44. Munhoz RP, Li JY, Kurtinecz M, et al. Evaluation of the pull test technique in assessing postural instability in Parkinson's disease. Neurology 2004;62(1):125-127.

45. Giladi N, Shabtai H, Simon ES, Biran S, Tal J, Korczyn AD. Construction of freezing of gait questionnaire for patients with Parkinsonism. Parkinsonism Relat Disord 2000;6(3):165-170.

46. Giladi N, Tal J, Azulay T, et al. Validation of the freezing of gait questionnaire in patients with Parkinson's disease. Mov Disord 2009;24(5):655-661.

47. Chee R, Murphy A, Danoudis M, Georgiou-Karistianis N, lansek R. Gait freezing in Parkinson's disease and the stride length sequence effect interaction. Brain 2009;132(Pt 8):2151-2160. 
48. Defer $\mathrm{GL}$, Widner $\mathrm{H}$, Marie RM, Remy $\mathrm{P}$, Levivier $\mathrm{M}$. Core assessment program for surgical interventional therapies in Parkinson's disease (CAPSIT-PD). Mov Disord 1999;14(4):572-584.

49. Koop MM, Andrzejewski A, Hill BC, Heit G, Bronte-Stewart HM. Improvement in a quantitative measure of bradykinesia after microelectrode recording in patients with Parkinson's disease during deep brain stimulation surgery. Mov Disord 2006;21(5):673-678.

50. Khan S, Mooney L, Plaha $\mathrm{P}$, et al. Outcomes from stimulation of the caudal zona incerta and pedunculopontine nucleus in patients with Parkinson's disease. Br J Neurosurg 2011;25(2):273-280. 51. Moreau C, Defebvre L, Destee A, et al. STN-DBS frequency effects on freezing of gait in advanced Parkinson disease. Neurology 2008;71(2):80-84.

52. Hazrati LN, Wong JC, Hamani C, et al. Clinicopathological study in progressive supranuclear palsy with pedunculopontine stimulation. Mov Disord 2012;27(10):1304-1307.

53. Acar F, Acar G, Bir LS, Gedik B, Oguzhanoglu A. Deep brain stimulation of the pedunculopontine nucleus in a patient with freezing of gait. Stereotact Funct Neurosurg 2011;89(4):214-219.

54. Jenkinson N, Brittain JS, Hicks SL, Kennard C, Aziz TZ. On the origin of oscillopsia during pedunculopontine stimulation. Stereotact Funct Neurosurg 2012;90(2):124-129.

55. Aviles-Olmos I, Foltynie T, Panicker J, et al. Urinary incontinence following deep brain stimulation of the pedunculopontine nucleus. Acta Neurochir (Wien) 2011;153(12):2357-2360. 56. Khan S, Javed S, Mooney L, et al. Clinical outcomes from bilateral versus unilateral stimulation of the pedunculopontine nucleus with and without concomitant caudal zona incerta region stimulation in Parkinson's disease. Br J Neurosurg 2012;26(5):722-725.

57. Mazzone $P$, Paoloni $M$, Mangone $M$, et al. Unilateral deep brain stimulation of the pedunculopontine tegmental nucleus in idiopathic Parkinson's disease: effects on gait initiation and performance. Gait Posture 2014;40(3):357-362.

58. Thevathasan W, Pogosyan A, Hyam JA, et al. A block to pre-prepared movement in gait freezing, relieved by pedunculopontine nucleus stimulation. Brain 2011;134(Pt 7):2085-2095.

59. Peppe A, Pierantozzi M, Chiavalon C, et al. Deep brain stimulation of the pedunculopontine tegmentum and subthalamic nucleus: effects on gait in Parkinson's disease. Gait Posture

2010;32(4):512-518.

60. Faist M, Xie J, Kurz D, et al. Effect of bilateral subthalamic nucleus stimulation on gait in Parkinson's disease. Brain 2001;124(Pt 8):1590-1600.

61. Goetz CG, Tilley BC, Shaftman SR, et al. Movement Disorder Society-sponsored revision of the Unified Parkinson's Disease Rating Scale (MDS-UPDRS): scale presentation and clinimetric testing results. Mov Disord 2008;23(15):2129-2170.

62. Shih LC, Vanderhorst VG, Lozano AM, Hamani C, Moro E. Improvement of pisa syndrome with contralateral pedunculopontine stimulation. Mov Disord 2013;28(4):555-556.

63. Ricciardi L, Piano C, Bentivoglio AR, Fasano A. Long-term effects of pedunculopontine nucleus stimulation for Pisa syndrome. Parkinsonism Relat Disord 2014;20(12):1445-1446.

64. Doherty KM, van de Warrenburg BP, Peralta MC, et al. Postural deformities in Parkinson's disease. Lancet Neurol 2011;10(6):538-549.

65. Mazzone P, Padua L, Falisi G, Insola A, Florio TM, Scarnati E. Unilateral deep brain stimulation of the pedunculopontine tegmental nucleus improves oromotor movements in Parkinson's disease. Brain stimulation 2012;5(4):634-641.

66. Zanini S, Moschella V, Stefani A, et al. Grammar improvement following deep brain stimulation of the subthalamic and the pedunculopontine nuclei in advanced Parkinson's disease: a pilot study. Parkinsonism Relat Disord 2009;15(8):606-609.

67. Pinto S, Ferraye $M$, Espesser $R$, et al. Stimulation of the pedunculopontine nucleus area in Parkinson's disease: effects on speech and intelligibility. Brain 2014;137(Pt 10):2759-2772.

68. Temel Y, Blokland A, Ackermans L, et al. Differential effects of subthalamic nucleus stimulation in advanced Parkinson disease on reaction time performance. Exp Brain Res 2006;169(3):389-399. 
69. Brown RG, Dowsey PL, Brown P, et al. Impact of deep brain stimulation on upper limb akinesia in Parkinson's disease. Ann Neurol 1999;45(4):473-488.

70. Nandi D, Liu X, Winter JL, Aziz TZ, Stein JF. Deep brain stimulation of the pedunculopontine region in the normal non-human primate. J Clin Neurosci 2002;9(2):170-174.

71. Fischer J, Schwiecker K, Bittner V, et al. Modulation of Attentional Processing by Deep Brain Stimulation of the Pedunculopontine Nucleus Region in Patients With Parkinsonian Disorders. Neuropsychology 2015.

72. Camicioli R, Oken BS, Sexton G, Kaye JA, Nutt JG. Verbal fluency task affects gait in Parkinson's disease with motor freezing. J Geriatr Psychiatry Neurol 1998;11(4):181-185.

73. Giladi N, Hausdorff JM. The role of mental function in the pathogenesis of freezing of gait in Parkinson's disease. J Neurol Sci 2006;248(1-2):173-176.

74. Costa A, Carlesimo GA, Caltagirone C, et al. Effects of deep brain stimulation of the peduncolopontine area on working memory tasks in patients with Parkinson's disease. Parkinsonism Relat Disord 2010;16(1):64-67.

75. Alessandro S, Ceravolo R, Brusa L, et al. Non-motor functions in parkinsonian patients implanted in the pedunculopontine nucleus: focus on sleep and cognitive domains. J Neurol Sci 2010;289(1-2):44-48.

76. Ricciardi L, Piano C, Rita Bentivoglio A, Fasano A. Pedunculopontine Nucleus Stimulation in Parkinson's Disease Dementia. Biological psychiatry 2015;77(8):e35-40.

77. Ceravolo R, Brusa L, Galati S, et al. Low frequency stimulation of the nucleus tegmenti pedunculopontini increases cortical metabolism in parkinsonian patients. Eur J Neurol 2011;18(6):842-849.

78. Ballanger B, Lozano AM, Moro E, et al. Cerebral blood flow changes induced by pedunculopontine nucleus stimulation in patients with advanced Parkinson's disease: a [(15)O $\mathrm{H} 2 \mathrm{O}$ PET study. Hum Brain Mapp 2009;30(12):3901-3909.

79. Strafella AP, Lozano AM, Ballanger B, Poon YY, Lang AE, Moro E. rCBF changes associated with PPN stimulation in a patient with Parkinson's disease: a PET study. Mov Disord 2008;23(7):1051-1054.

80. Romigi A, Placidi F, Peppe A, et al. Pedunculopontine nucleus stimulation influences REM sleep in Parkinson's disease. Eur J Neurol 2008;15(7):e64-65.

81. Arnulf I, Ferraye M, Fraix V, et al. Sleep induced by stimulation in the human pedunculopontine nucleus area. Ann Neurol 2010 67(4):546-549.

82. Lim AS, Moro E, Lozano AM, et al. Selective enhancement of rapid eye movement sleep by deep brain stimulation of the human pons. Ann Neurol 2009;66(1):110-114.

83. Saper CB, Scammell TE, Lu J. Hypothalamic regulation of sleep and circadian rhythms. Nature 2005;437(7063):1257-1263.

84. Lim AS, Lozano AM, Moro E, et al. Characterization of REM-sleep associated ponto-geniculooccipital waves in the human pons. Sleep 2007;30(7):823-827.

85. Peeraully T, Yong MH, Chokroverty S, Tan EK. Sleep and Parkinson's disease: a review of case-control polysomnography studies. Mov Disord 2012;27(14):1729-1737.

86. Plihal W, Born J. Effects of early and late nocturnal sleep on declarative and procedural memory. J Cogn Neurosci 1997;9(4):534-547.

87. Piallat B, Chabardes S, Torres N, et al. Gait is associated with an increase in tonic firing of the sub-cuneiform nucleus neurons. Neuroscience 2009;158(4):1201-1205.

88. Selikhova M, Williams DR, Kempster PA, Holton JL, Revesz T, Lees AJ. A clinico-pathological study of subtypes in Parkinson's disease. Brain 2009;132(Pt 11):2947-2957. 


\begin{tabular}{|c|c|c|c|c|c|c|c|c|}
\hline Study: Author, Date & Centre(s) & $\begin{array}{c}\text { Number of } \\
\text { patients }\end{array}$ & PPN DBS type & $\begin{array}{l}\text { PPN DBS } \\
\text { frequency }\end{array}$ & $\begin{array}{l}\text { Follow up } \\
\text { duration }\end{array}$ & Study design & Outcome measures & Gait and Falls Outcomes \\
\hline Ferraye et al, $2009^{3}$ & Grenoble & 6 & $\begin{array}{l}\text { Bilateral rostral } \\
\text { with STN DBS }\end{array}$ & $15-25 \mathrm{~Hz}$ & 12 months & Double blind & $\begin{array}{l}\text { UPDRS part II, FOGQ, } \\
\text { Freezing duration }\end{array}$ & $\begin{array}{c}\text { Reduced FOG in } 4 / 6 \text { patients. Reduced falls in } 1 / 6 \\
\text { patients }\end{array}$ \\
\hline Moro et al, $2010^{4}$ & Toronto & 6 & $\begin{array}{l}\text { Unilateral rostral } \\
\text { Lone PPN DBS }\end{array}$ & $50-70 \mathrm{~Hz}$ & 12 months & Double blind & UPDRS part II & $\begin{array}{l}\text { Reduced falls in all patients. Reduced FOG in } 5 / 6 \text { patients } \\
\text { at } 3 \text { months and } 3 / 6 \text { patients at } 12 \text { months }\end{array}$ \\
\hline $\begin{array}{l}\text { Thevathasan et al, } \\
2011^{6}\end{array}$ & Brisbane & 5 & $\begin{array}{l}\text { Bilateral caudal } \\
\text { Lone PPN DBS }\end{array}$ & $35 \mathrm{~Hz}$ & 24 months & Open label & GFQ and FOGQ & $\begin{array}{c}\text { Reduced FOG and falls in all } 5 \text { patients at } 6 \text { months and } 2 \\
\text { years (but lesser benefit at } 2 \text { years) }\end{array}$ \\
\hline $\begin{array}{l}\text { Thevathasan et al, } \\
2012^{5}\end{array}$ & $\begin{array}{l}\text { Oxford and } \\
\text { Brisbane }\end{array}$ & 7 & $\begin{array}{l}\text { Bilateral caudal } \\
\text { Lone PPN DBS }\end{array}$ & $35-40 \mathrm{~Hz}$ & 2-30 months & $\begin{array}{l}\text { Single session } \\
\text { double blind }\end{array}$ & $\begin{array}{c}\text { Duration of FOG on gait } \\
\text { analysis }\end{array}$ & $\begin{array}{c}\text { Significant improvement in FOG off medication. Bilateral } \\
\text { DBS better than unilateral }\end{array}$ \\
\hline Welter et al, $2015^{7}$ & Paris & 6 & $\begin{array}{l}\text { Bilateral rostral and } \\
\text { caudal } \\
\text { Lone PPN DBS }\end{array}$ & $20-40 \mathrm{~Hz}$ & 6 months & Double blind & $\begin{array}{l}\text { UPDRS part II, RSGE, Gait } \\
\text { initiation from a force } \\
\text { platform }\end{array}$ & $\begin{array}{l}\text { One patient required device removal due to infection. } \\
\text { One patient sustained a brainstem bleed. Of the } \\
\text { remaining } 4 \text { patients - reduced FOG in } 3 \text { and reduced } \\
\text { falls in } 2\end{array}$ \\
\hline Mestre et al, $2016^{38}$ & Toronto & 8 & $\begin{array}{l}\text { Unilateral rostral } \\
\text { Lone PPN DBS }\end{array}$ & $70 \mathrm{~Hz}$ & 24-48 months & Double blind & UPDRS part II & $\begin{array}{l}\text { Reduced falls at } 2 \text { years in } 6 / 8 \text { patients and at } 4 \text { years in } \\
4 / 6 \text { patients. Reduced FOG at } 2 \text { years in } 5 / 8 \text { patients and } \\
\text { at } 4 \text { years in } 4 / 6 \text { patients. }\end{array}$ \\
\hline
\end{tabular}

Table: Studies of at least 5 patients that have specifically measured the impact of PPN DBS on gait freezing and falls. Abbreviations; UPDRS = unified Parkinson's disease rating scale, GFQ = Gait and falls questionnaire, FOGQ = freezing of gait questionnaire, RSGE = Rating scale for gait evaluation, FOG = freezing of gait

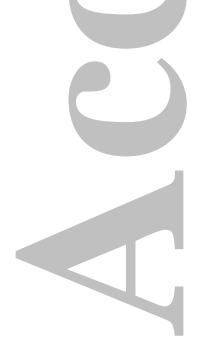




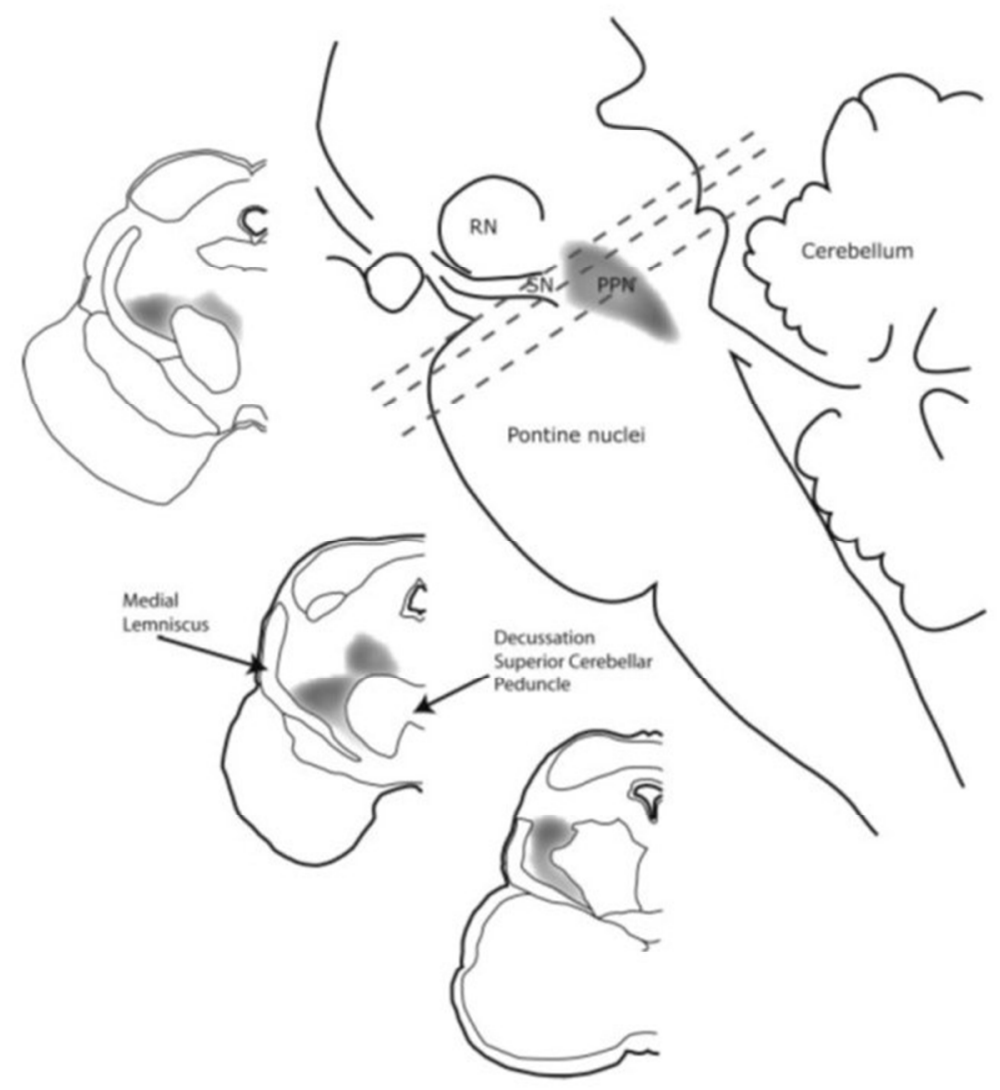

Figure 1: Three axial sections through the human brainstem showing the position of the PPN. The level of the three sections is indicated by the dashed lines in the para-sagittal cartoon of the brainstem. RN, Red Nucleus. PPN, Pedunculopontine Nucleus. SN, Substantia Nigra. Adapted from Olszewski and Baxter (1954). Figure adapted from Jenkinson et al, Movement disorders 2008.2

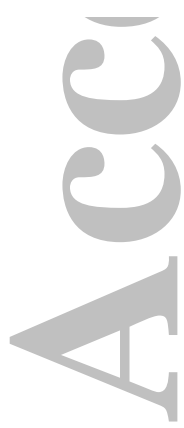

$71 \times 60 \mathrm{~mm}(300 \times 300 \mathrm{DPI})$ 


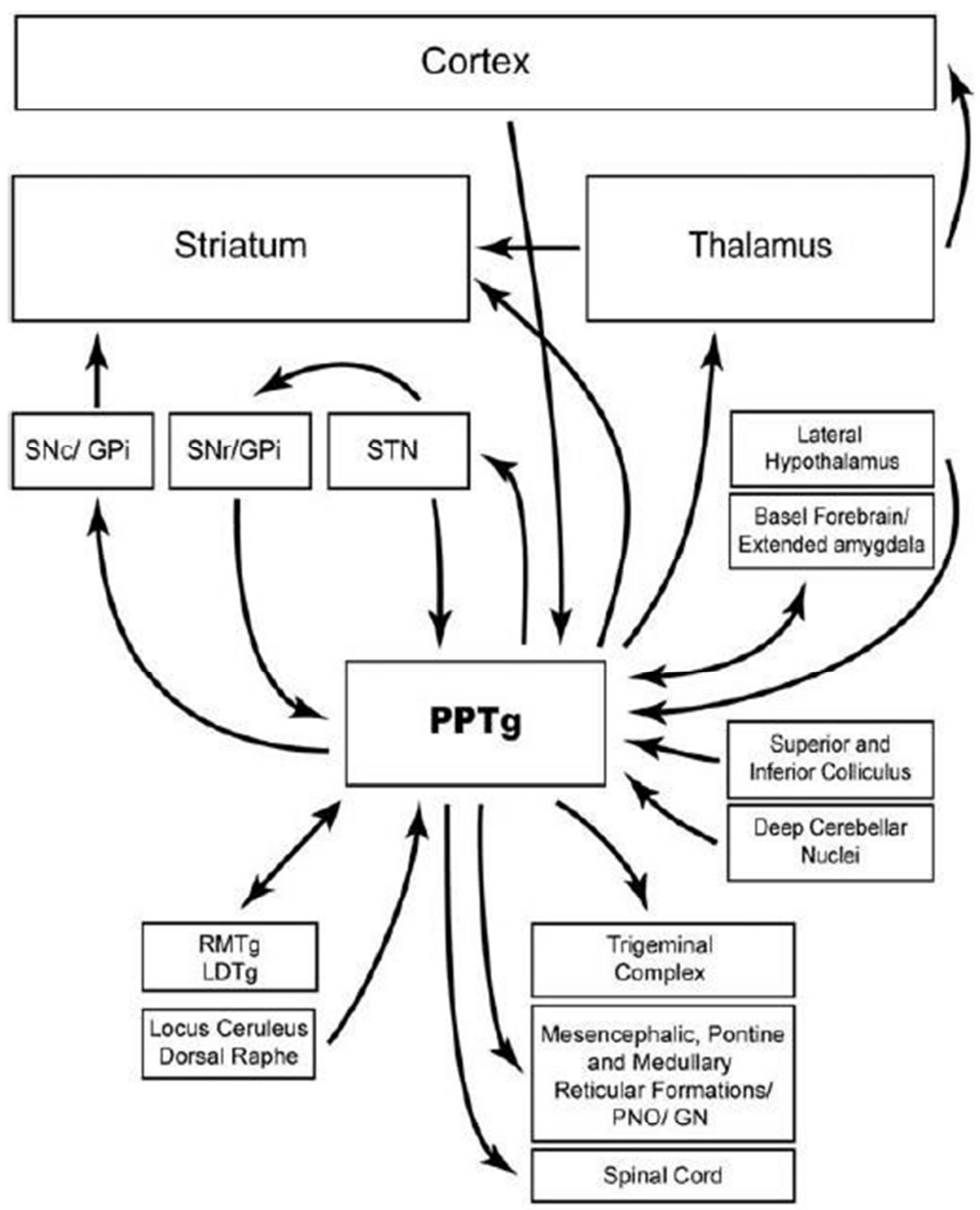

Figure 2: Schematic illustration of the connectivity of the PPN. Distinct functional types of PPN subpopulations innervate basal ganglia and in turn basal ganglia structures project back to different neuronal populations in the PPN. It is important to note that projections form the PPN to the structures illustrated here are not wholly independent: cholinergic and non-cholinergic neurons from topographically distributed populations send collaterals to several structures (e.g. to thalamus and basal ganglia). Likewise, descending collaterals of ascending axons contribute to a dense innervation of structures in the lower brainstem, pons, medulla, and spinal cord. Figure adapted from Gut et al, Movement disorders 2016.3

$$
51 \times 55 \mathrm{~mm}(300 \times 300 \text { DPI })
$$




\section{Pedunculopontine nucleus deep brain stimulation in Parkinson's disease: A clinical review}

Wesley Thevathasan, DPhil FRACP, ${ }^{1}$ Bettina Debu, PhD, ${ }^{2}$ Tipu Aziz, FRCS, ${ }^{3}$ Bastiaan R. Bloem, MD PhD, ${ }^{4}$ Christian Blahak, MD ${ }^{5}$ Christopher Butson, $\mathrm{PhD},{ }^{6}$ Virginie Czernecki, PhD,${ }^{7}$ Thomas Foltynie, PhD FRCP,${ }^{8}$ Valerie Fraix, MD PhD, ${ }^{2}$ David Grabli, MD PhD, ${ }^{9}$ Carole Joint, RN PhD, ${ }^{3}$ Andres M. Lozano, MD PhD, ${ }^{10}$ Michael S. Okun, MD, ${ }^{11}$ Jill Ostrem, MD, ${ }^{12}$ Nicola Pavese, PhD FRCP,${ }^{13}$ Christoph Schrader, MD,${ }^{14}$ Chun-Hwei Tai, MD, ${ }^{15}$ Joachim K. Krauss, MD, ${ }^{16}$ Elena Moro MD PhD, ${ }^{2}$

On behalf of the MDS PPN DBS working group in collaboration with WSSFN*

1. Department of Medicine, Royal Melbourne Hospital, University of Melbourne, Australia and the Bionics Institute of Australia, Melbourne, Australia

2. Movement Disorders Center, Division of Neurology, CHU Grenoble, Grenoble Alpes University, Grenoble, France

3. Department of Neurosurgery, John Radcliffe Hospital, University of Oxford, UK

4. Department of Neurology, Donders Institute for Brain, Cognition and Behaviour, Radboud University, Nijmegen, the Netherlands

5. Department of Neurology, Universitätsmedizin Mannheim, University of Heidelberg, Heidelberg, Germany

6. Department of Bioengineering, Scientific Computing and Imaging (SCI) Institute, University of Utah, Salt Lake City, USA

7. Department of Neurology, Institut de Cerveau et de la Moelle épinière, Sorbonne Universités, UPMC Université, Paris, France

8. Sobell Department of Motor Neuroscience, UCL Institute of Neurology, United Kingdom

9. Department of Neurology, Assistance Publique-Hôpitaux de Paris, Pitié-Salpêtière University Hospital, Paris, France

10. Department of Neurosurgery, Toronto Western Hospital, University of Toronto, Toronto, Canada

11. Departments of Neurology and Neurosurgery, University of Florida Center for Movement Disorders, Gainseville, USA 
12. Department of Neurology, UCSF Movement Disorder and Neuromodulation Center, University of California, San Francisco, USA

13. Institute of Neuroscience, Newcastle University, Newcastle upon Tyne, UK and Department of Clinical Medicine, Centre for Functionally Integrative Neuroscience, University of Aarhus, Aarhus, Denmark and Department of Neurology, Hannover Medical School, Hannover, Germany

14. Department of Neurology, National Taiwan University Hospital, College of Medicine, National Taiwan University, Taipei, Taiwan

15. Department of Neurosurgery, Hannover Medical School, Hannover, Germany

* See Appendix

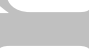

Corresponding author:

Elena Moro, MD, PhD

Centre Hospitalier Universitaire de Grenoble, Grenoble Alpes University

BP21738043 Grenoble CEDEX 09 France

$\mathrm{Fax}+33476765631$

E-mail: emoro@,chu-grenoble.fr
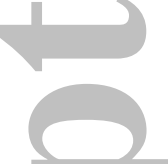

Word count: 4988

Running Title: Clinical review of PPN DBS

Key words: deep brain stimulation, gait freezing, Parkinson's disease, pedunculopontine nucleus

Financial disclosure/Conflict of interest: The MDS PPN DBS working group in collaboration with WSSFN was supported by an unrestricted educational grant from Medtronic.

Disclosures from individual authors are cited on each copyright transfer form.

Funding sources: The MDS PPN DBS working group in collaboration with WSSFN was supported by an unrestricted educational grant from Medtronic. 


\section{ABSTRACT}

Pedunculopontine nucleus region deep brain stimulation (DBS) is a promising but experimental therapy for axial motor deficits in Parkinson's disease (PD), particularly gait freezing and falls. Here, we summarise the clinical application and outcomes reported over the last 10 years. The published dataset is limited - comprising less than a hundred cases. Furthermore, there is great variability in clinical methodology, both between and within surgical centres. The commonest indication has been severe medication refractory gait freezing (often associated with postural instability). Some patients received lone pedunculopontine nucleus DBS (unilateral or bilateral) and some received co-stimulation of the subthalamic nucleus or internal pallidum. Both rostral and caudal pedunculopontine nucleus subregions have been targeted. However, spread of stimulation and variance in targeting means that neighbouring brainstem regions may be implicated in any response. Low stimulation frequencies are typically employed (20-80 Hertz). The fluctuating nature of gait freezing can confound programming and outcome assessments of outcomes. Whilst firm conclusions cannot be drawn on therapeutic efficacy, the literature suggests that medication refractory gait freezing and falls can improve. The impact on postural instability is unclear. Most groups report a lack of benefit on gait or limb akinesia or dopaminergic medication requirements. The key question is whether pedunculopontine nucleus DBS can improve quality of life in PD. So far, the evidence supporting such an effect is minimal. Development of pedunculopontine nucleus DBS to become a reliable, established therapy would likely

require a collaborative effort between experienced centres worldwide collaborative effort to clarify biomarkers predictive of response and the optimal clinical methodology. 


\section{INTRODUCTION}

The pedunculopontine nucleus (PPN, also known as the pedunculopontine tegmental nucleus or PPTg) is a collection of heterogeneous neurons at the junction of the midbrain and pons. ${ }^{1,2}$ PPN neurons express a range of neurotransmitters but perhaps most prominently acetylcholine. ${ }^{2}$ The PPN displays substantial reciprocal connectivity with the cortex via the thalamus, basal ganglia, and spinal cord. ${ }^{3}$ A long and rich history of research in animals suggests that the PPN may affect locomotion, the startle response, states of arousal and even reward. ${ }^{4-8}$ Of relevance to gait, the PPN has been considered a key component of the “Mesencephalic Locomotor Region' - an area where electrical stimulation in decerebrated animals can induce locomotor-like activity, although the relevance of this concept to the therapeutic impact of PPN DBS is debated..$^{2,3}$

PPN DBS has developed as an experimental therapy for axial motor deficits in Parkinson's disease (PD), particularly those which are poorly responsive to subthalamic nucleus (STN) and globus pallidus internus (GPi) DBS. ${ }^{9-11}$ Axial deficits such as gait freezing and postural instability are major contributors to impaired quality of life in PD. The initial emergence of PPN DBS, therefore, raised much excitement. However, it became apparent that the therapeutic outcomes from PPN DBS were variable and often disappointing, both within and between surgical centres. ${ }^{12-16}$ This variability may reflect a fundamental limitation of the target or alternatively that the methodology has not been optimised yet.

To try and progress the field, a Working Group was approved as a bi-societal endeavour of the international Movement Disorders Society (MDS) and the World Society for Stereotactic and Functional Neurosurgery (WSSFN). This group encompasses neurologists, neurosurgeons, neurophysiologists, neuropsychologists, and electrical engineers with 
expertise on the PPN and/or PPN DBS. The initial objective was to summarise, analyse and publish on the state of the field.

The surgical aspects of this work (surgical anatomy and techniques) have been recently published in a specialized neurosurgical journal. ${ }^{17}{ }^{18}$ This paper deals with medical aspects of PPN DBS including the clinical application and outcomes to date.

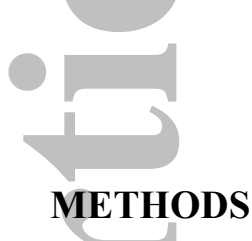

\section{Literature search}

The PubMed database was searched from 1990 to March 2017 using the key words: deep brain stimulation, Parkinson's disease, pedunculopontine nucleus, surgery, treatment. Only publications in English reporting clinical outcomes of PPN DBS in PD were selected.

\section{Questions and consensus process}

The Executive Committee of the Working Group formulated several questions which were distributed to groups of authors according to their expertise - as with previous Task Forces. ${ }^{19}$, ${ }^{20}$ The answers were organized into the manuscript, and reviewed by the Executive Committee and the complete task force at multiple international meetings. Areas of disagreement were discussed and modified according to Delphi techniques until consensus was reached. ${ }^{21}$ The literature was updated during the work.

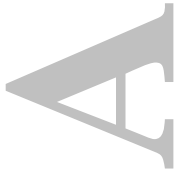

\section{RESULTS}

Less than 100 patients with PD implanted with PPN DBS have been published. 9, 10, 12-16, 22-27 Between and even within surgical centres, there has been substantial variation and often 
evolution in clinical methodology. Therefore, we must acknowledge the many limitations and confounds from these reports. First, the clinical application of PPN DBS employed so far does not necessarily reflect the optimal methodology. Secondly, the location of where therapeutic effects from stimulation arise has not been established yet. For example, electrodes have been implanted in both rostral and caudal PPN subregions. ${ }^{25,26}$ Furthermore, in some cases, stimulation may actually have been directed at networks involving neighbouring structures including the cuneiform and peripeduncular nuclei. ${ }^{27,28}$ In any case, the range of stimulation parameters typically employed means that a range of networks may be implicated in any response. ${ }^{24,28}$ For example, the differing stimulation frequencies applied to the PPN (10 to $80 \mathrm{~Hz})$ may affect the selectivity of neural elements. ${ }^{29}$ For this reason, we always imply stimulation of the PPN region when we discuss PPN DBS. Thirdly, the limited and heterogeneous dataset prevents us drawing firm conclusions regarding the scope of clinical impact. This dataset includes case reports, open label series, double blinded single time point assessments, and longer term double blinded studies (table). Finally, PPN DBS has evolved as a treatment for axial motor impairment, particularly gait freezing and falls. The impact of PPN DBS on other domains have generally been reported as incidental observations.

\section{$\underline{\text { Clinical application }}$}

\section{Indication}

After initial reports suggested improvement in gait freezing from PPN DBS in PD, the typical indications became medication refractory gait freezing and falls. ${ }^{9,12-14,16}$ Therefore, most patients implanted with PPN DBS have fallen into one of these two groups; 
1. Patients with PD who exhibit early and severe gait freezing resistant to medication as the dominant cause of disability are candidates for lone PPN DBS. ${ }^{30}$ This is an unusual subgroup, perhaps comprising around $5 \%$ of patients with PD. ${ }^{30}$ Indeed, some of these patients may later declare features of an atypical parkinsonian disorder. ${ }^{31}$ Patients with medication responsive freezing and motor fluctuations are candidates for established therapies such as STN or GPi DBS. ${ }^{32,33}$

2. Patients with PD who develop medication resistant gait freezing during STN or GPi DBS can be candidate for PPN DBS. ${ }^{12,15,22,25}$ However, co-stimulation of both the PPN and STN/GPi could cause an interaction between stimulation at these sites. ${ }^{34}$ On the one hand, this could be synergistic, with STN or GPi DBS adding improvement to akinesia and 'off' freezing compared with lone PPN DBS. ${ }^{22}$ On the other hand, high frequency STN or GPi DBS could transmit to the PPN via their extensive reciprocal connections and counteract PPN DBS. ${ }^{2,7,35}$

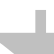

\section{Target selection}

The exact location and the anatomical boundaries of the PPN are controversial. ${ }^{36-38}$

Furthermore, the precise location of stimulation in the brainstem is poorly reflected by commissural coordinates. Therefore, some studies have reported the location of PPN stimulation relative to local landmarks. A detailed discussion on the surgical anatomy and targeting is found in our companion papers. ${ }^{17,18}$ The following two issues are raised as important for understanding the medical management of PPN DBS.

\section{Rostral vs. Caudal PPN stimulation}

Over time, two topographic regions of the PPN have been posited, rostral and caudal. Studies have reported spatially segregated patterns of local field potentials recorded from PPN 
electrodes in patients with PD. Alpha band oscillations in the caudal subregion (around 4mm below the pontomesencephalic junction) were reported to correlate with gait and freezing, ${ }^{37}$ whereas beta band oscillations in the rostral subregion (around the level of the inferior colliculus) were not found to correlate with gait (real or imagined). ${ }^{37,39}$ Two studies reported very limited clinical data that further raised the hypothesis that caudal PPN DBS may be more effective than rostral PPN DBS for gait freezing. ${ }^{37,40}$ Given the surgical trajectory usually runs along the long axis of the PPN, it is feasible to target both subregions with the same electrode giving the option to activate either.

\section{Unilateral vs. Bilateral PPN Stimulation}

The relative efficacy of unilateral versus bilateral PPN stimulation is controversial. Some practitioners elected to implant unilaterally, given the bilateral connectivity of each PPN and the greater risks inherent in bilateral implantation. ${ }^{2,13}$ In a small double blind study employing spatiotemporal gait analysis, bilateral PPN stimulation in seven patients was reported as more effective than unilateral PPN stimulation for 'off medication' gait freezing. ${ }^{41}$ Additionally, some patients implanted with unilateral PPN DBS, have been reported to further benefit from contralateral PPN implantation. ${ }^{42}$

\section{Outcome assessments}

A common method to assess outcomes has been the Unified Parkinson's disease rating scale (UPDRS). ${ }^{43}$ The 'pull test' item of the UPDRS was the only method used in most studies to assess postural instability, however this test is said to suffer poor reliability and scaling (score/4). ${ }^{44}$ Gait freezing exhibits substantial fluctuation which makes accurate measurement difficult. Some studies of PPN DBS employed specific instruments to capture gait freezing such as the Gait and Falls Questionnaire (GFQ, score/64), and the Freezing of Gait 
Questionnaire (FOGQ, score/24). ${ }^{45,46}$ Even fewer studies employed objective laboratory methods including spatiotemporal gait analysis using a walkway with embedded pressure sensors, step tracking with shoe mounted pressure sensors, and fast Fourier transformation of trunk accelerometer data. ${ }^{12,37,41}$ However, such laboratory methods can confounded by the propensity of freezing to disappear under observation. ${ }^{47}$ Some studies therefore employed potent triggers of gait freezing such as turning on the spot in a confined space. ${ }^{12,41}$ Individual studies have attempted to assess non-motor deficits such as sleep, cognition, psychiatric state, quality of life and adverse events using instruments commonly used to assess DBS in PD. ${ }^{48}$

\section{Postoperative management}

\section{Programming}

Titration of PPN DBS can be complex and time consuming. Factors include the fluctuating nature of gait freezing, the unpredictable degree of benefit and the prolonged latencies (days to weeks) reported for benefits to emerge. ${ }^{12-14}$ Furthermore, an acute microlesion or 'stun' effect has been described where gait freezing improves in the early postoperative period prior to activation of stimulation. ${ }^{16,37,49}$

The major stimulation variables explored have been stimulation location along the electrode (see discussion of rostral vs caudal DBS above) and frequency. Other reported parameters have been fairly restricted (e.g. typical pulse width range $60-90$ usec, $^{13,35}$ and voltage range from 0.8 to $3.6 \mathrm{~V}$ ) with monopolar or bipolar configuration. ${ }^{12,13,23}$

All studies have reported that low frequencies $(<80 \mathrm{~Hz})$ of PPN DBS seem optimal for motor deficits. Studies of bilateral PPN DBS have reported that 20-35 Hz stimulation was useful for gait freezing. ${ }^{12,14,22,23}$ One study found that patients responded best to higher frequencies (60 $-80 \mathrm{~Hz}){ }^{13}$ This study differed in two critical respects - the use of unilateral rather than 
bilateral PPN DBS and the additional goal of treating co-morbid postural instability. ${ }^{13}$ Two studies have specifically investigated frequency effects of PPN DBS in PD. One study explored differing very low frequencies $(5-35 \mathrm{~Hz})$ on reaction time. ${ }^{23}$ This study found that 20-35 Hz PPN DBS was superior to $5 \mathrm{~Hz}$ and $10 \mathrm{~Hz}$ stimulation. ${ }^{23}$ Another study directly compared the impact of bilateral low frequency $(10-25 \mathrm{~Hz})$ versus higher frequency $(60-80$ Hz) PPN DBS on gait freezing, akinesia and sleepiness. ${ }^{35}$ Seven of nine patients had less gait freezing with low frequency PPN DBS. ${ }^{35}$ Bilateral higher frequency PPN DBS was associated with worsened akinesia and sleepiness.

Titration of medication and stimulation of other targets

The lack of benefit of PPN DBS on akinesia (see below) has meant that either dopaminergic medication or co-stimulation of conventional targets (STN or GPi) has been required to maintain the 'on' state. ${ }^{12,14}$ PPN DBS has not been widely reported to substantially change dopaminergic medical requirements. In some patients, an ideal motor benefit was achieved by reducing the high frequencies normally employed in the STN (e.g. from $130 \mathrm{~Hz}$ to $80 \mathrm{~Hz}$ ) during co-stimulation of the PPN. ${ }^{15,50}$ Even with lone STN DBS, it has been reported that lower stimulation frequencies may improve 'on' freezing, so it is unclear if this represents a specific interaction between the two stimulation locations. ${ }^{51}$

\section{Stimulation and implantation side effects}

Reversible side effects resulting from PPN region DBS or the microlesion effect from implantation mostly relate likely to involvement of neighbouring structures. ${ }^{17}$ These include:

1. Sensory phenomena. Contralateral paraesthesia likely reflects current spread to the medial lemniscus. ${ }^{12,22,52}$ This typically habituates over seconds to minutes. A more profound and even painful sensation may reflect spread into the more lateral spinothalamic tract. ${ }^{52}$ In a 
single case stimulation caused ipsilateral pain consistent with spread to the trigeminal nucleus. ${ }^{53}$

2. Oscillopsia. Typically, reported by patients as 'shimmering' vision. Infra-red eye tracking demonstrates nystagmus at the frequency of DBS ipsilateral to stimulation. Stimulation of fibres in the uncinate fasciculus of the cerebellum and the superior cerebellar peduncle (which in turn stimulate the saccadic premotor neurones) is hypothesized. ${ }^{54}$

3. Limb myoclonus. This may reflect involvement of the ipsilateral cerebellar peduncle/decussation. ${ }^{12}$

4. Urge urinary incontinence with phasic detrusor over activity. This was described in a patient from the time of implantation and which recovered over months. ${ }^{55}$ The nearby pontine micturition centre was implicated. ${ }^{55}$

\section{Outcomes}

\section{Motor Impact}

\section{Gait freezing}

Short term $(<2$ years $)$

Reduced gait freezing appears to be the major therapeutic benefit of PPN DBS, evident from the earliest reports. ${ }^{9,}{ }^{24}$ However, the evidence base remains modest, with studies being small (up to ten patients) and ranging from unblinded open label series to double blinded studies with controls. ${ }^{12-16,41}$ These studies suggest that PPN DBS can improve gait freezing in some patients, in both off and on medication states. ${ }^{13,41}$ Two surgical centres (Toronto and Grenoble) employed unilateral or bilateral stimulation to the rostral PPN, and reported variable and overall modest improvements. ${ }^{12,13}$ Another two surgical centres (Oxford and Brisbane), applied bilateral stimulation to the caudal PPN region, and also reported modest 
but more substantial benefits. ${ }^{14,41}$ Two more surgical centres (Rome and Bristol) reported that PPN DBS improved motor function including gait, but did not isolate gait freezing as a separate outcome measure. ${ }^{15,50,56,57}$ There are also single case reports of PPN DBS in PD with overall mixed results. ${ }^{25,26}$

Some inferences regarding the degree of efficacy of PPN DBS on freezing can be attempted by using selected studies that reported scores from individual patients. ${ }^{12-14,41}$ Pooled results from three studies that reported individual scores for item 14 (freezing) of the UPDRS part II, revealed an overall improvement with PPN DBS of $30 \%(\mathrm{~N}=15$, mean score $2.2 / 4$ reduced to 1.5/4) when on medication. ${ }^{12,13,16}$ Results of patients from two centres assessed with the GFQ (reflecting function whilst medicated) revealed an improvement of $39 \%(\mathrm{~N}=7$, mean 45.7 to 27.7$).{ }^{58}$ One double-blind controlled study assessed freezing using spatiotemporal gait analysis while off medication, and reported an overall $64.6 \%$ improvement $(\mathrm{N}=7$, freezing duration 31.1 to 11.0 seconds). ${ }^{41}$ Thus, so far, PPN DBS has been reported to partially improve but not abolish gait freezing. Whether such partial benefits are clinically meaningful is unclear but perhaps captured in quality of life assessments (see below). Furthermore, there is insufficient data to comment on whether PPN DBS differentially affects all the various aspects of gait freezing that have been described.

Longer term (> 2 years)

One recent paper reported the outcomes at four years after unilateral PPN DBS implantation in six patients with PD, with double blinded assessments off and on stimulation (two weeks in each condition). ${ }^{42}$ There was persistent benefit in four of the six patients on gait freezing and falls.

\section{Other aspects of Gait}


Two studies suggested that PPN DBS could alter a variety of spatiotemporal parameters during unconstrained gait - that is, when walking freely straight ahead. ${ }^{57,59}$ However, these studies had methodological issues, including a set order of conditions, unblinded assessments, the potential influence of fluctuating medication state and washout of STN DBS. ${ }^{59}$ In contrast, in a double-blinded, controlled study employing spatiotemporal gait analysis, the impact of lone PPN DBS on gait was assessed when off medication. ${ }^{41}$ This study reported a benefit of PPN DBS on gait freezing. During unconstrained walking, patients with freezing had reduced step length and increased step length variability compared to patients without freezing. However, these deficits were unchanged by PPN DBS. ${ }^{41}$ This study suggests that the impact of PPN DBS differs from that of levodopa and STN DBS, which improve step length and thereby presumably also improve off medication freezing. ${ }^{47,60}$ Therefore, the therapeutic benefits of PPN and STN DBS (or levodopa) on gait would be predicted to be complementary although this remains to be formally tested.

\section{Balance}

The impact of PPN DBS on overall balance is uncertain.

Improved postural instability was specifically cited as a potential benefit in one of the earliest reports of PPN DBS. ${ }^{9}$ However, few studies have specifically isolated the impact on postural instability - and any benefit has been variable and often not detected. ${ }^{9,12,13,16}$ One issue may be the shortcomings in the assessment tool for postural instability used by these studies - the clinical 'pull test' (item 30 of the UPDRS part III and item 3.12 of the MDS-UPDRS, score/4). ${ }^{43,61}$ The pull test may not be sufficiently sensitive or reliable to detect a clinically meaningful change. ${ }^{14,44}$ Another issue may relate to DBS programming as it has been suggested that different frequencies of stimulation may be needed to improve postural instability compared with gait freezing. ${ }^{35}$ Further research is needed into this area. 
Two recent papers suggest that other aspects of balance may be modulated by PPN DBS. ${ }^{16,27}$ In these studies, PPN DBS appeared to alter measures of postural sway in centre of pressure during stance. ${ }^{16}$ In one study, PPN DBS improved anticipatory postural adjustments. ${ }^{16}$ In another study, PPN DBS (during STN stimulation) appeared to improve vestibular perceptual thresholds. ${ }^{27}$ The net functional consequences of such effects remain to be established.

\section{Falls}

An improvement in falls frequency with PPN DBS has been documented using item 13 of the UPDRS part II (score/4), components of the Rating Scale for Gait Evaluation and the GFQ, and patient diaries. ${ }^{12-14,16,23,42}$ Fewer falls with PPN DBS has been a consistently reported therapeutic benefit, occurring even in studies where any benefit on freezing or postural instability was modest or not found. ${ }^{13,23}$ This could reflect that falls frequency is a more certain and sensitive biomarker of the response to PPN DBS. It is unclear if falls are reduced due to less freezing, less postural instability, or another mechanism (for example, a paradoxical reduction in falls due to less ambulation or greater use of gait aids has not been excluded). In two studies, reduced falls were unrelated to freezing, which suggests that the effect is somewhat independent of any reduction in gait freezing. ${ }^{13,23}$ The benefit of PPN DBS on falls is reported to endure over the long term in one study. ${ }^{42}$

\section{Axial deformity}

Two reports describe an apparent benefit of unilateral PPN DBS on Pisa syndrome. In one report, the electrode was contralateral to the side of lateral lean and improvement was sustained over 14 months, and documented with videotape assessment. ${ }^{62}$ In the other report, the electrode was ipsilateral to the side of lateral lean and improvement wore off over 3 years. The effect in this case was documented with a wall mounted goniometer. ${ }^{63}$ Such findings 
seem to mirror the debate regarding whether the direction of lean in Pisa syndrome relates to the side most affected by parkinsonism. ${ }^{64}$

\section{Speech}

Three studies have specifically assessed the impact of PPN DBS on speech. ${ }^{65-67}$ In an initial study, unilateral PPN DBS was suggested to improve oromotor movements, raising hopes that speech could improve. ${ }^{65}$ However, a recent double-blinded study of six patients found that bilateral PPN DBS worsened measures of phonation time and speech diadokokinesis with overall mixed effects on speech intelligibility. ${ }^{67}$ Considering the current evidence, it is not clear whether the overall impact of PPN DBS on speech is helpful or detrimental.

\section{Akinesia, rigidity and tremor}

Almost all studies of PPN DBS have observed no substantial benefit on akinesia, rigidity or tremor as assessed by items $1-26$ of the UPDRS part III. ${ }^{12-14,22}$ However, one group has consistently reported a possible benefit of PPN DBS on these items, both off and on medication. ${ }^{9}, 15,50,56$ These patients were generally also receiving STN DBS raising the possibility that persistent washout effects could have influenced the results. Furthermore, PPN DBS does not significantly change dopaminergic medication requirements and there is additional motor benefit following STN DBS. ${ }^{12,22}$ PPN DBS does not uniformly yield the

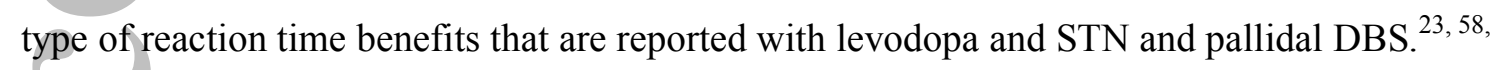
${ }^{68,69}$ Furthermore, double blinded spatiotemporal gait analysis has revealed no change to step length with PPN DBS. ${ }^{41}$ Importantly, in one double-blind study, bilateral PPN DBS applied at medium frequencies $(60-80 \mathrm{~Hz})$ significantly worsened akinesia scores compared with low frequency stimulation $(15-25 \mathrm{~Hz})^{7,35,70}$

\section{Reaction time}


Studies of at least eight patients that assessed the impact of PPN DBS on reaction time have reported a benefit most prominent in simple reaction time tasks. ${ }^{23,58,71}$ This reaction time benefit was reported to affect the entire reaction time distribution curve and not just outliers, argued to reflect a motor impact rather than augmented attention. ${ }^{23}$ A further study suggested that this motor effect could be isolated to enhanced release of pre-programmed motor responses, supported by the absence of the Start React phenomenon in patients with gait freezing that was restored by PPN DBS. ${ }^{58}$

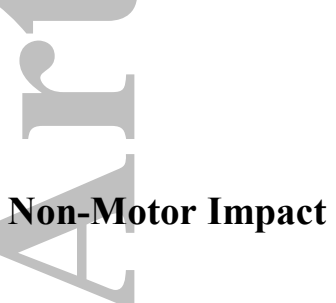

\section{Cognition and mood}

That the PPN comprises part of the reticular activating system has raised the question of whether PPN DBS may improve attention, especially as attentional deficits are implicated in the pathogenesis of gait freezing. ${ }^{72,73}$ A recent study found that bilateral PPN DBS improved simple reaction times without a warning cue but not a go/no-go or divided attention task. ${ }^{71}$ There was a strong trend that PPN DBS also improved simple reaction times with a warning cue $(p=0.07)$. However, on the basis that this latter result was not significant, the authors argued that PPN DBS improved phasic arousal rather than a motor effect. Though, with only eight patients in the study, this may simply reflect insufficient power. Additionally, two further studies (discussed in the section above) suggested that the selective impact of PPN DBS on certain aspects of reaction time is likely due to enhanced motor performance. ${ }^{23,58}$ Thus, it seems currently that there is insufficient evidence to support that PPN DBS augments alertness or general attention.

Several studies of PPN DBS have performed cross sectional cognitive assessments. Two studies found no consistent change in the Mattis Dementia Rating Scale or a composite 
assessment of frontal lobe function in six patients with PPN DBS. ${ }^{12,16}$ However, several studies from the Rome group have reported substantial improvements with PPN DBS on frontal lobe cognition in small numbers of patients. For example, two such studies suggested improvements in performance on an n-back task and various tasks of executive functioning but with limited information regarding the methodology. ${ }^{74,75}$ One case report claimed that PPN DBS improved measures in all tested cognitive domains including attention, memory and language, and was perhaps modulated by attentional improvements although this effect may have been due to intercurrent factors. ${ }^{76}$ These authors also reported that PPN DBS increased prefrontal glucose utilisation using FDG-PET with associated improvements in delayed recall and executive functioning. ${ }^{77}$ However, such frontal changes with PPN DBS were not found on regional cerebral blood flow PET in three other studies, where blood flow changes appeared restricted to subcortical and sensorimotor cortical areas. ${ }^{15,78,79}$

In one study of six patients, PPN DBS did not consistently change scores of the Beck Depression Inventory or the Starkstein Apathy Scale. ${ }^{12}$ In another study of four patients, anxiety and depression did not change, as assessed by questionnaires (Brief Anxiety Scale, Montgomery, and Asberg Depression Scale). ${ }^{16}$ Other major clinical studies (with $\geq 5$ patients) have not formally assessed psychiatric outcomes. ${ }^{13,14,22}$ However, clinically obvious psychiatric effects from PPN DBS were not reported in these studies.

\section{Sleep}

Three studies have specifically assessed whether PPN DBS affects sleep in parkinsonian patients. ${ }^{80-82}$ The results suggest a marked impact on switching between sleep states, particularly the promotion of rapid eye movement (REM) sleep. This is consistent with decades of animal research. ${ }^{83}$ 
Two studies assessed patients using overnight polysomnography, and both reported that PPN DBS roughly doubled the proportion of REM sleep. ${ }^{80,82}$ In one study of 5 patients with PD or PSP, unilateral PPN DBS increased nightly REM sleep time (mean 35 to 61 minutes) and percentage REM sleep (mean 8 to $14 \%$ ) compared with no stimulation. ${ }^{82}$ Importantly, this study found that the increased REM sleep was due to an increased frequency rather than duration of REM sleep episodes. Non-REM sleep was unchanged by PPN DBS. Two patients experienced REM sleep behavioural disturbance and this persisted with PPN DBS.

The increased REM sleep episodes with PPN DBS suggest that there may be an underlying impact on transitioning between sleep states. In support of this notion, an early study detected phasic potentials during and before REM sleep from PPN electrodes consistent with pontogeniculo-occipital waves. ${ }^{84}$ One study reported two patients in whom PPN DBS could provoke sleep from a state of wakefulness, assessed clinically and with electroencephalography. ${ }^{81}$ These patients were alert during low frequency PPN DBS $(10 \mathrm{~Hz}$ or $25 \mathrm{~Hz}$ ). In one patient, abrupt withdrawal of this low frequency PPN DBS reproducibly triggered short periods of REM sleep. In both patients, initiation of high frequency PPN DBS $(80 \mathrm{~Hz})$ could precipitate non-REM sleep.

It is unclear what, if any, functional consequence may result from increased REM sleep with PPN DBS. Some but not all studies suggest that REM sleep may decline in PD. ${ }^{85}$ REM sleep is postulated to improve memory consolidation, particularly that of procedural learning. ${ }^{86}$ Whether this has mechanistic relevance to the motor impact of PPN DBS is unknown.

\section{Surgical risks}

At this stage, there does not appear to be any contraindication that is specific to PPN DBS relative to other forms of DBS for Parkinson's disease. However, patients would need to be 
counselled that the occurrence of even a small haemorrhage in the brainstem could have devastating consequences. ${ }^{16,67}$

\section{Quality of Life}

Two double blinded studies have reported on the impact of PPN DBS on quality of life using the Parkinson's Disease Questionnaire-39 (PDQ-39). One study of six patients found that PPN DBS did not consistently change scores of the PDQ-39. ${ }^{12}$ However in five of six patients, PPN DBS improved scores in the mobility subsection of the PDQ-39. ${ }^{12}$ In a second

report of six patients, two patients had severe adverse events (infection requiring device explanation and brainstem hemorrhage). In the remaining four patients in that study, quality of life improved significantly. ${ }^{16}$

\section{DISCUSSION}

Despite more than ten-years history of the use of PPN DBS in patients with PD, the cohort of implanted patients worldwide remains limited. ${ }^{9,}{ }^{10}$ Additionally, only a few centres have generated the bulk of the cases and published literature. ${ }^{12-15,22}$ These factors limit the strength and thus inferences that can be drawn from the dataset.

We have presented a summary of the clinical application of PPN DBS employed to date. Clinical methodologies have varied greatly. For example, in some cases stimulation is even argued to be directed at neighbouring structures including the cuneiform and peripeduncular nuclei. ${ }^{36,87}$ However, it is conceivable that variance in stimulation location could identify a more effective target than the PPN itself. What is evident is that fundamental aspects of the clinical application of PPN DBS remain unclear, including if there are specific biomarkers of 
response to guide patient selection, the ideal stimulation location and parameters of stimulation. Indeed, these areas could interact together, e.g., it is possible that postural instability may benefit from stimulation of a different PPN subregion, and with different stimulation parameters compared with gait freezing. ${ }^{13}$

Whilst acknowledging the limitations of the dataset, the available evidence supports that PPN DBS has the potential to improve gait freezing in both the off and on medication states, and can reduce falls in some patients. ${ }^{12-14,41}$ The impact on postural instability is unclear. The degree of improvement is highly variable - both between and within surgical centres. On average, PPN DBS offers a reduction and not resolution of freezing and falls. There is no known preoperative factor that predicts such benefits. The variability of benefit may reflect the differing clinical methods employed. For example, it is difficult to compare outcomes of patients implanted with lone PPN DBS compared with those also receiving stimulation in other targets (often with reciprocal connections to the PPN). Additionally, axial deficits are difficult to capture with the available clinical scales and more objective measures are needed. ${ }^{44}$ For example, the consistent benefit of PPN DBS on falls across studies may simply reflect that it is an unambiguous and sensitive biomarker of response. Furthermore, it should be acknowledged that disease progression in the subgroup of patients with severe gait freezing and balance disturbance who are suitable for this therapy is often more aggressive. ${ }^{88}$ This means that long term outcomes will be particularly important in gauging success of this intervention.

PPN DBS does not clearly improve other aspects of gait such as gait akinesia. ${ }^{41}$ Moreover, the evidence does not support any benefit for limb akinesia, rigidity or tremor and thus dopaminergic medication requirements do not substantially change after PPN DBS. ${ }^{12,13,23}$ 
Regarding non-motor symptoms, the current evidence does not strongly support any major impact on cognition outside of enhanced motor performance. ${ }^{58}$ PPN DBS appears to increase REM sleep. ${ }^{82}$ Whether this increased REM sleep has any functional consequences, either beneficial or not, is unknown.

The clinically relevant question is whether PPN DBS can improve quality of life in patients with PD. So far, the available evidence supporting this ideal is very modest. ${ }^{12,16}$ It is clearly our hope that refinement of the clinical application of PPN DBS will yield the type of robust and consistent benefits seen with DBS of established targets in PD such as the STN and GPi. However, we acknowledge the less attractive possibility that the therapeutic action of the target itself may be the issue. For example, gait freezing is considered a complex deficit which involves dysfunction in widespread networks including attentional and motor systems, both cortical and brainstem. Relief of the latter may only have capacity to yield a circumscribed benefit. However, even if this were the case, there could still be an identifiable subgroup of patients where this benefit could improve quality of life and/or have a synergistic relationship with other emerging therapies. Of course, any benefit must be contrasted against risks of brainstem implantation.

So, what are the next steps? First, acknowledge that every centre has successes and failures. We need to identify what is different about patients who respond positively, and to identify the key predictors of therapeutic efficacy. To achieve this, we need to pool the experience of centres that implant the PPN. develop a high quality dataset of the growing worldwide experience of delivering PPN DBS. One initial approach would be a multicentre database capturing agreed measures of the clinical application (such as stimulation location) and outcomes. Only once the clinical methodology of PPN DBS has been further developed would it be appropriate to consider a multicentre randomised controlled trial to assess the impact on quality of life. 


\section{ACKNOWLEDGEMENTS}

The MDS PPN DBS working group in collaboration with WSSFN was supported by an

unrestricted educational grant from Medtronic.

\section{AUTHORS ROLES}

(1) Research Project: A. Conception, B. Organization, C. Execution;

(2) Statistical Analysis: A. Design, B. Execution, C. Review and Critique;

(3) Manuscript Preparation: A. Writing of the First Draft, B. Review and Critique

WT: 1BC, 3AB. BD: 1C, 3B. TA: 1ABC, 3B. BRB: 1ABC, 3B. C.Blahak: 1C, 3B. C. Butson: 1C, 3B. VC: 1C, 3B. TF: 1C, 3B. VF: 1C, 3B. DG: 1C, 3B. AML: 1ABC, 3B. CJ:

1C, 3B. MSO: 1ABC, 3B. JO: 1C, 3B. NP: 1C, 3B. CS: 1C, 3B. CT: 1C, 3B. JKK: 1ABC, 3B. EM: $1 \mathrm{ABC}, 3 \mathrm{~B}$.

\section{APPENDIX}

The Members of the Pedunculopontine Area DBS Working Group: T. Aziz (United Kingdom); C. Blahak (Germany), B. Bloem (The Netherlands), P. Brown (United Kingdom), C. Butson (USA), S. Chabardes (France), TJ Coyne (Australia), V. Czernecki (France), B. Debu (France), T. Foltynie (United Kingdom), E. Fonoff (Brazil), V. Fraix (France), K. Foote (USA), D. Grabli (France), C. Hamani (Canada), E.C. Hirsch (France), W. Hutchison (Canada), J.K. Krauss (Germany), C. Joint (United Kingdom), AM Lozano (Canada), P. Mazzone (Italy), E. Moro (France), M. Okun (USA), J. Ostrem (USA), N. Pavese (United Kingdom), C. Schrader (Germany), J. Stein (United Kingdom), C-H Tai (Taiwan), W. Thevathasan (Australia), I. Veletzas (Greece).

\section{REFERENCES}

1. Jacobsohn L. Uber die Kerne des menschlichen Hirnstamms:(Medulla oblongata, Pons, und Pedunculus cerebri). Anhang zuden Abhandlungen der Kgl Preuss, Akad d Wiss 1911.

2. Jenkinson N, Nandi D, Muthusamy K, et al. Anatomy, physiology, and pathophysiology of the pedunculopontine nucleus. Mov Disord 2008.

3. Gut NK, Winn P. The pedunculopontine tegmental nucleus-A functional hypothesis from the comparative literature. Mov Disord 2016;31(5):615-624. 
4. Garcia-Rill E, Houser CR, Skinner RD, Smith W, Woodward DJ. Locomotion-inducing sites in the vicinity of the pedunculopontine nucleus. Brain Res Bull 1987;18(6):731-738.

5. Winn P. Experimental studies of pedunculopontine functions: are they motor, sensory or integrative? Parkinsonism Relat Disord 2008;14 Suppl 2:S194-198.

6. Mena-Segovia J, Sims HM, Magill PJ, Bolam JP. Cholinergic brainstem neurons modulate cortical gamma activity during slow oscillations. J Physiol 2008.

7. Jenkinson N, Nandi D, Miall RC, Stein JF, Aziz TZ. Pedunculopontine nucleus stimulation improves akinesia in a Parkinsonian monkey. Neuroreport 2004;15(17):2621-2624.

8. Nandi D, Aziz TZ, Giladi N, Winter J, Stein JF. Reversal of akinesia in experimental parkinsonism by GABA antagonist microinjections in the pedunculopontine nucleus. Brain 2002;125(Pt 11):2418-2430.

9. Plaha P, Gill SS. Bilateral deep brain stimulation of the pedunculopontine nucleus for Parkinson's disease. Neuroreport 2005;16(17):1883-1887.

10. Mazzone $P$, Lozano A, Stanzione $P$, et al. Implantation of human pedunculopontine nucleus: a safe and clinically relevant target in Parkinson's disease. Neuroreport 2005;16(17):1877-1881.

11. Fasano A, Aquino CC, Krauss JK, Honey CR, Bloem BR. Axial disability and deep brain stimulation in patients with Parkinson disease. Nat Rev Neurol 2015;11(2):98-110.

12. Ferraye MU, Debu B, Fraix V, et al. Effects of pedunculopontine nucleus area stimulation on gait disorders in Parkinson's disease. Brain 2009;133(Pt 1):205-214.

13. Moro E, Hamani C, Poon YY, et al. Unilateral pedunculopontine stimulation improves falls in Parkinson's disease. Brain 2010;133(Pt 1):215-224.

14. Thevathasan W, Coyne TJ, Hyam JA, et al. Pedunculopontine nucleus stimulation improves gait freezing in Parkinson disease. Neurosurgery 2011;69(6):1248-1253.

15. Khan S, Gill SS, Mooney L, et al. Combined pedunculopontine-subthalamic stimulation in Parkinson disease. Neurology 2012;78(14):1090-1095.

16. Welter ML, Demain A, Ewenczyk C, et al. PPNa-DBS for gait and balance disorders in Parkinson's disease: a double-blind, randomised study. J Neurol 2015;262(6):1515-1525.

17. Hamani C, Aziz T, Bloem BR, et al. Pedunculopontine Nucleus Region Deep Brain Stimulation in Parkinson Disease: Surgical Anatomy and Terminology. Stereotact Funct Neurosurg 2016;94(5):298-306.

18. Hamani C, Lozano AM, Mazzone PA, et al. Pedunculopontine Nucleus Region Deep Brain Stimulation in Parkinson Disease: Surgical Techniques, Side Effects, and Postoperative Imaging. Stereotact Funct Neurosurg 2016;94(5):307-319.

19. Benabid AL, Deuschl G, Lang AE, Lyons KE, Rezai AR. Deep brain stimulation for Parkinson's disease. Mov Disord 2006;21 Suppl 14:S168-170.

20. Moro E, Albanese A, Krauss JK, Metman LV, Vidailhet M, Hariz MI. Guest editors' introduction. Mov Disord 2011;26 Suppl 1:S1-2.

21. Linstone HA, and Murray Turoff, eds. . The Delphi method: Techniques and applications. . Reading, MA: Addison-Wesley, 1975.

22. Stefani A, Lozano AM, Peppe A, et al. Bilateral deep brain stimulation of the pedunculopontine and subthalamic nuclei in severe Parkinson's disease. Brain 2007;130(Pt 6):15961607.

23. Thevathasan W, Silburn PA, Brooker $\mathrm{H}$, et al. The impact of low-frequency stimulation of the pedunculopontine nucleus region on reaction time in parkinsonism. J Neurol Neurosurg Psychiatry 2010;81(10):1099-1104.

24. Pereira EA, Muthusamy KA, De Pennington N, Joint CA, Aziz TZ. Deep brain stimulation of the pedunculopontine nucleus in Parkinson's disease. Preliminary experience at Oxford. Br J Neurosurg 2008;22 Suppl 1:S41-44.

25. Schrader C, Seehaus F, Capelle HH, Windhagen A, Windhagen H, Krauss JK. Effects of pedunculopontine area and pallidal DBS on gait ignition in Parkinson's disease. Brain stimulation 2013;6(6):856-859. 
26. Liu HG, Zhang K, Yang AC, Zhang JG. Deep brain stimulation of the subthalamic and pedunculopontine nucleus in a patient with Parkinson's disease. J Korean Neurosurg Soc 2015;57(4):303-306.

27. Yousif $N$, Bhatt $H$, Bain PG, Nandi D, Seemungal BM. The effect of pedunculopontine nucleus deep brain stimulation on postural sway and vestibular perception. Eur J Neurol 2016;23(3):668-670. 28. Zrinzo L, Zrinzo LV, Tisch S, et al. Stereotactic localization of the human pedunculopontine nucleus: atlas-based coordinates and validation of a magnetic resonance imaging protocol for direct localization. Brain 2008;131(Pt 6):1588-1598.

29. Kringelbach ML, Jenkinson N, Owen SL, Aziz TZ. Translational principles of deep brain stimulation. Nat Rev Neurosci 2007;8(8):623-635.

30. Giladi N, McDermott MP, Fahn S, et al. Freezing of gait in PD: prospective assessment in the DATATOP cohort. Neurology 2001;56(12):1712-1721.

31. Scelzo E, Lozano AM, Hamani C, et al. Peduncolopontine nucleus stimulation in progressive supranuclear palsy: a randomised trial. J Neurol Neurosurg Psychiatry 2017.

32. Deuschl G, Schade-Brittinger C, Krack P, et al. A randomized trial of deep-brain stimulation for Parkinson's disease. N Engl J Med 2006;355(9):896-908.

33. Follett KA, Weaver FM, Stern M, et al. Pallidal versus subthalamic deep-brain stimulation for Parkinson's disease. N Engl J Med 2010;362(22):2077-2091.

34. Ferraye MU, Debu B, Fraix V, et al. Subthalamic nucleus versus pedunculopontine nucleus stimulation in Parkinson disease: synergy or antagonism? J Neural Transm 2011;118(10):1469-1475.

35. Nosko D, Ferraye MU, Fraix V, et al. Low-frequency versus high-frequency stimulation of the pedunculopontine nucleus area in Parkinson's disease: a randomised controlled trial. J Neurol Neurosurg Psychiatry 2014.

36. Zrinzo L, Zrinzo LV, Hariz M. The peripeduncular nucleus: a novel target for deep brain stimulation? Neuroreport 2007;18(12):1301-1302.

37. Thevathasan W, Pogosyan A, Hyam JA, et al. Alpha oscillations in the pedunculopontine nucleus correlate with gait performance in parkinsonism. Brain 2012;135(Pt 1):148-160.

38. Yelnik J. PPN or PPD, what is the target for deep brain stimulation in Parkinson's disease?

Brain 2007;130(Pt 9):e79; author reply e80.

39. Tattersall TL, Stratton PG, Coyne TJ, et al. Imagined gait modulates neuronal network dynamics in the human pedunculopontine nucleus. Nat Neurosci 2014;17(3):449-454.

40. Fu RZ NM, Adams A, et al. . Sub-caudal pedunculopontine nucleus (PPN) deep brain stimulation (DBS) best predicts improvements in freezing of gait questionnaire (FOGQ) scores in Parkinson's disease patients. . Movement Disorders(29 Suppl 1):1193 2014.

41. Thevathasan W, Cole MH, Graepel CL, et al. A spatiotemporal analysis of gait freezing and the impact of pedunculopontine nucleus stimulation. Brain 2012;135(Pt 5):1446-1454.

42. Mestre TA, Sidiropoulos C, Hamani C, et al. Long-term double-blinded unilateral pedunculopontine area stimulation in Parkinson's disease. Movement disorders 2016;31(10):15701574.

43. Fahn S ER, UPDRS program members. Unified Parkinson's Disease Rating Scale In: Fahn S MC, Goldstein M, Calne DB, ed. Recent Developments in Parkinson's Disease. Florham Park, NJ: Macmillan Healthcare Information, 1987:153-163, 293-304.

44. Munhoz RP, Li JY, Kurtinecz M, et al. Evaluation of the pull test technique in assessing postural instability in Parkinson's disease. Neurology 2004;62(1):125-127.

45. Giladi N, Shabtai H, Simon ES, Biran S, Tal J, Korczyn AD. Construction of freezing of gait questionnaire for patients with Parkinsonism. Parkinsonism Relat Disord 2000;6(3):165-170.

46. Giladi N, Tal J, Azulay T, et al. Validation of the freezing of gait questionnaire in patients with Parkinson's disease. Mov Disord 2009;24(5):655-661.

47. Chee R, Murphy A, Danoudis M, Georgiou-Karistianis N, lansek R. Gait freezing in Parkinson's disease and the stride length sequence effect interaction. Brain 2009;132(Pt 8):2151-2160. 
48. Defer $\mathrm{GL}$, Widner $\mathrm{H}$, Marie RM, Remy $\mathrm{P}$, Levivier $\mathrm{M}$. Core assessment program for surgical interventional therapies in Parkinson's disease (CAPSIT-PD). Mov Disord 1999;14(4):572-584.

49. Koop MM, Andrzejewski A, Hill BC, Heit G, Bronte-Stewart HM. Improvement in a quantitative measure of bradykinesia after microelectrode recording in patients with Parkinson's disease during deep brain stimulation surgery. Mov Disord 2006;21(5):673-678.

50. Khan S, Mooney L, Plaha $\mathrm{P}$, et al. Outcomes from stimulation of the caudal zona incerta and pedunculopontine nucleus in patients with Parkinson's disease. Br J Neurosurg 2011;25(2):273-280. 51. Moreau C, Defebvre L, Destee A, et al. STN-DBS frequency effects on freezing of gait in advanced Parkinson disease. Neurology 2008;71(2):80-84.

52. Hazrati LN, Wong JC, Hamani C, et al. Clinicopathological study in progressive supranuclear palsy with pedunculopontine stimulation. Mov Disord 2012;27(10):1304-1307.

53. Acar F, Acar G, Bir LS, Gedik B, Oguzhanoglu A. Deep brain stimulation of the pedunculopontine nucleus in a patient with freezing of gait. Stereotact Funct Neurosurg 2011;89(4):214-219.

54. Jenkinson N, Brittain JS, Hicks SL, Kennard C, Aziz TZ. On the origin of oscillopsia during pedunculopontine stimulation. Stereotact Funct Neurosurg 2012;90(2):124-129.

55. Aviles-Olmos I, Foltynie T, Panicker J, et al. Urinary incontinence following deep brain stimulation of the pedunculopontine nucleus. Acta Neurochir (Wien) 2011;153(12):2357-2360. 56. Khan S, Javed S, Mooney L, et al. Clinical outcomes from bilateral versus unilateral stimulation of the pedunculopontine nucleus with and without concomitant caudal zona incerta region stimulation in Parkinson's disease. Br J Neurosurg 2012;26(5):722-725.

57. Mazzone $\mathrm{P}$, Paoloni $\mathrm{M}$, Mangone $\mathrm{M}$, et al. Unilateral deep brain stimulation of the pedunculopontine tegmental nucleus in idiopathic Parkinson's disease: effects on gait initiation and performance. Gait Posture 2014;40(3):357-362.

58. Thevathasan W, Pogosyan A, Hyam JA, et al. A block to pre-prepared movement in gait freezing, relieved by pedunculopontine nucleus stimulation. Brain 2011;134(Pt 7):2085-2095.

59. Peppe A, Pierantozzi M, Chiavalon C, et al. Deep brain stimulation of the pedunculopontine tegmentum and subthalamic nucleus: effects on gait in Parkinson's disease. Gait Posture 2010;32(4):512-518.

60. Faist M, Xie J, Kurz D, et al. Effect of bilateral subthalamic nucleus stimulation on gait in Parkinson's disease. Brain 2001;124(Pt 8):1590-1600.

61. Goetz CG, Tilley BC, Shaftman SR, et al. Movement Disorder Society-sponsored revision of the Unified Parkinson's Disease Rating Scale (MDS-UPDRS): scale presentation and clinimetric testing results. Mov Disord 2008;23(15):2129-2170.

62. Shih LC, Vanderhorst VG, Lozano AM, Hamani C, Moro E. Improvement of pisa syndrome with contralateral pedunculopontine stimulation. Mov Disord 2013;28(4):555-556.

63. Ricciardi L, Piano C, Bentivoglio AR, Fasano A. Long-term effects of pedunculopontine nucleus stimulation for Pisa syndrome. Parkinsonism Relat Disord 2014;20(12):1445-1446.

64. Doherty KM, van de Warrenburg BP, Peralta MC, et al. Postural deformities in Parkinson's disease. Lancet Neurol 2011;10(6):538-549.

65. Mazzone P, Padua L, Falisi G, Insola A, Florio TM, Scarnati E. Unilateral deep brain stimulation of the pedunculopontine tegmental nucleus improves oromotor movements in Parkinson's disease. Brain stimulation 2012;5(4):634-641.

66. Zanini S, Moschella V, Stefani A, et al. Grammar improvement following deep brain stimulation of the subthalamic and the pedunculopontine nuclei in advanced Parkinson's disease: a pilot study. Parkinsonism Relat Disord 2009;15(8):606-609.

67. Pinto $S$, Ferraye $M$, Espesser $R$, et al. Stimulation of the pedunculopontine nucleus area in Parkinson's disease: effects on speech and intelligibility. Brain 2014;137(Pt 10):2759-2772.

68. Temel Y, Blokland A, Ackermans L, et al. Differential effects of subthalamic nucleus stimulation in advanced Parkinson disease on reaction time performance. Exp Brain Res 2006;169(3):389-399. 
69. Brown RG, Dowsey PL, Brown P, et al. Impact of deep brain stimulation on upper limb akinesia in Parkinson's disease. Ann Neurol 1999;45(4):473-488.

70. Nandi D, Liu X, Winter JL, Aziz TZ, Stein JF. Deep brain stimulation of the pedunculopontine region in the normal non-human primate. J Clin Neurosci 2002;9(2):170-174.

71. Fischer J, Schwiecker K, Bittner V, et al. Modulation of Attentional Processing by Deep Brain Stimulation of the Pedunculopontine Nucleus Region in Patients With Parkinsonian Disorders. Neuropsychology 2015.

72. Camicioli R, Oken BS, Sexton G, Kaye JA, Nutt JG. Verbal fluency task affects gait in Parkinson's disease with motor freezing. J Geriatr Psychiatry Neurol 1998;11(4):181-185.

73. Giladi N, Hausdorff JM. The role of mental function in the pathogenesis of freezing of gait in Parkinson's disease. J Neurol Sci 2006;248(1-2):173-176.

74. Costa A, Carlesimo GA, Caltagirone C, et al. Effects of deep brain stimulation of the peduncolopontine area on working memory tasks in patients with Parkinson's disease. Parkinsonism Relat Disord 2010;16(1):64-67.

75. Alessandro S, Ceravolo R, Brusa L, et al. Non-motor functions in parkinsonian patients implanted in the pedunculopontine nucleus: focus on sleep and cognitive domains. J Neurol Sci 2010;289(1-2):44-48.

76. Ricciardi L, Piano C, Rita Bentivoglio A, Fasano A. Pedunculopontine Nucleus Stimulation in Parkinson's Disease Dementia. Biological psychiatry 2015;77(8):e35-40.

77. Ceravolo R, Brusa L, Galati S, et al. Low frequency stimulation of the nucleus tegmenti pedunculopontini increases cortical metabolism in parkinsonian patients. Eur J Neurol 2011;18(6):842-849.

78. Ballanger B, Lozano AM, Moro E, et al. Cerebral blood flow changes induced by pedunculopontine nucleus stimulation in patients with advanced Parkinson's disease: a [(15)O $\mathrm{H} 2 \mathrm{O}$ PET study. Hum Brain Mapp 2009;30(12):3901-3909.

79. Strafella AP, Lozano AM, Ballanger B, Poon YY, Lang AE, Moro E. rCBF changes associated with PPN stimulation in a patient with Parkinson's disease: a PET study. Mov Disord 2008;23(7):1051-1054.

80. Romigi A, Placidi F, Peppe A, et al. Pedunculopontine nucleus stimulation influences REM sleep in Parkinson's disease. Eur J Neurol 2008;15(7):e64-65.

81. Arnulf I, Ferraye M, Fraix V, et al. Sleep induced by stimulation in the human pedunculopontine nucleus area. Ann Neurol 2010 67(4):546-549.

82. Lim AS, Moro E, Lozano AM, et al. Selective enhancement of rapid eye movement sleep by deep brain stimulation of the human pons. Ann Neurol 2009;66(1):110-114.

83. Saper CB, Scammell TE, Lu J. Hypothalamic regulation of sleep and circadian rhythms. Nature 2005;437(7063):1257-1263.

84. Lim AS, Lozano AM, Moro E, et al. Characterization of REM-sleep associated ponto-geniculooccipital waves in the human pons. Sleep 2007;30(7):823-827.

85. Peeraully T, Yong MH, Chokroverty S, Tan EK. Sleep and Parkinson's disease: a review of case-control polysomnography studies. Mov Disord 2012;27(14):1729-1737.

86. Plihal W, Born J. Effects of early and late nocturnal sleep on declarative and procedural memory. J Cogn Neurosci 1997;9(4):534-547.

87. Piallat B, Chabardes S, Torres N, et al. Gait is associated with an increase in tonic firing of the sub-cuneiform nucleus neurons. Neuroscience 2009;158(4):1201-1205.

88. Selikhova M, Williams DR, Kempster PA, Holton JL, Revesz T, Lees AJ. A clinico-pathological study of subtypes in Parkinson's disease. Brain 2009;132(Pt 11):2947-2957. 


\section{University Library}

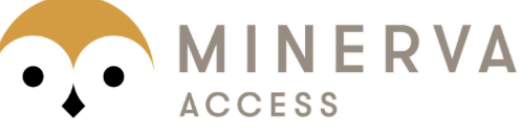

A gateway to Melbourne's research publications

Minerva Access is the Institutional Repository of The University of Melbourne

\section{Author/s:}

Thevathasan, W;Debu, B;Aziz, T;Bloem, BR;Blahak, C;Butson, C;Czernecki, V;Foltynie, T;Fraix, V;Grabli, D;Joint, C;Lozano, AM;Okun, MS;Ostrem, J;Pavese, N;Schrader, C;Tai, C$\mathrm{H} ;$ Krauss, JK;Moro, E

Title:

Pedunculopontine Nucleus Deep Brain Stimulation in Parkinson's Disease: A Clinical Review

Date:

2018-01-01

Citation:

Thevathasan, W., Debu, B., Aziz, T., Bloem, B. R., Blahak, C., Butson, C., Czernecki, V., Foltynie, T., Fraix, V., Grabli, D., Joint, C., Lozano, A. M., Okun, M. S., Ostrem, J., Pavese, N., Schrader, C., Tai, C. -H., Krauss, J. K. \& Moro, E. (2018). Pedunculopontine Nucleus Deep Brain Stimulation in Parkinson's Disease: A Clinical Review. MOVEMENT DISORDERS, 33 (1), pp.10-20. https://doi.org/10.1002/mds.27098.

Persistent Link:

http://hdl.handle.net/11343/293512 